Aus dem Institut für Anatomie und Zellbiologie

(Prof. Dr. rer. nat. J. Wilting)

im Zentrum Anatomie

der Medizinischen Fakultät der Universität Göttingen

\title{
Proliferationsuntersuchungen zur Entwicklung des Lymphgefäßsystems bei Wnt5a-transgenen Mäusen
}

\author{
INAUGURAL-DISSERTATION \\ zur Erlangung des Doktorgrades \\ für Zahnheilkunde \\ der Medizinischen Fakultät der \\ Georg-August-Universität zu Göttingen
}

vorgelegt von

Anna Haarmann

aus

Hamburg

Göttingen 2017 
Dekan:

Referent/in

Ko-Referent/in:

Drittreferent/in:
Prof. Dr. rer. nat. H. K. Kroemer

Prof. Dr. rer. nat. J. Wilting

Prof. Dr. med. Claudia Binder

Datum der mündlichen Prüfung: 07.05.2018 
Hiermit erkläre ich, die Dissertation mit dem Titel "Proliferationsuntersuchungen zur Entwicklung des Lymphgefäßsystems bei Wnt5a-transgenen Mäusen" eigenständig angefertigt und keine anderen als die von mir angegebenen Quellen und Hilfsmittel verwendet zu haben.

Göttingen, den 


\section{Inhaltsverzeichnis}

Abbildungsverzeichnis...........................................................................................................III

Tabellenverzeichnis .........................................................................................................................III

Abkürzungsverzeichnis ................................................................................................................ IV

$1 \quad$ Einleitung ................................................................................................... 1

1.1 Aufbau und Funktion des Lymphgefäßsystems ................................................... 1

1.2 Entwicklung des Lymphgefäßsystems …………………………………...... 2

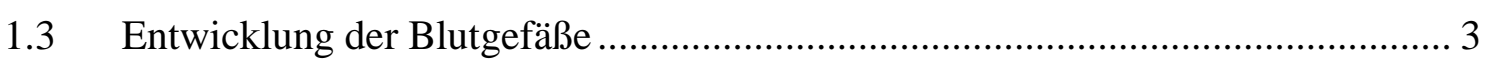

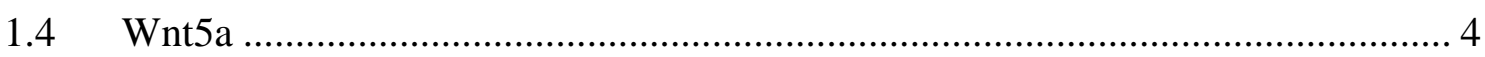

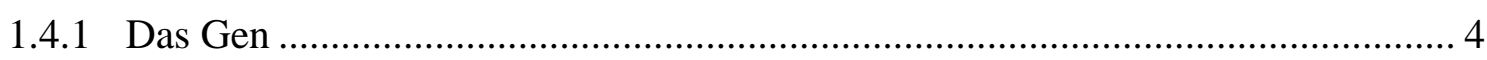

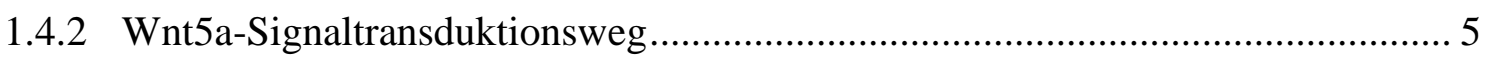

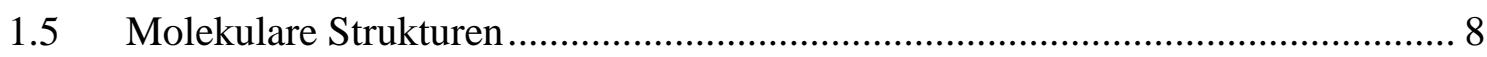

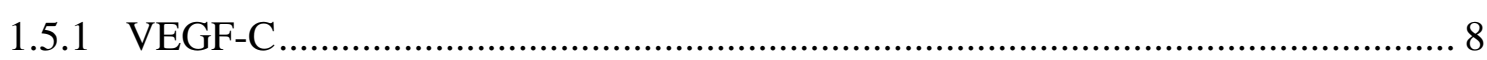

1.5.2 Marker von Lymphendothelzellen ............................................................ 8

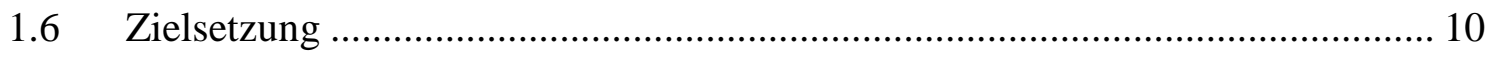

2 Material und Methoden ......................................................................................... 11

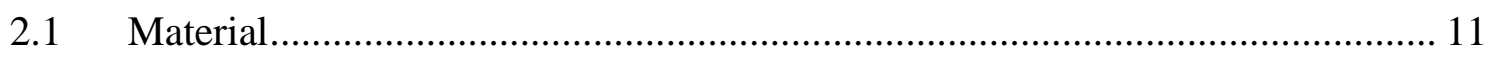

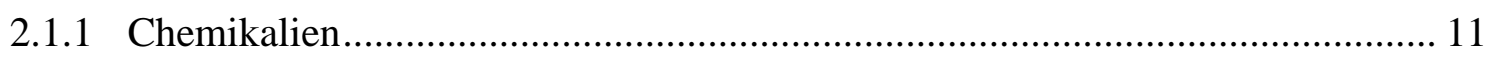

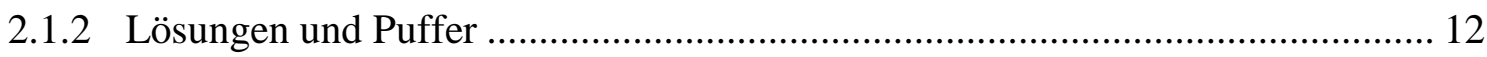

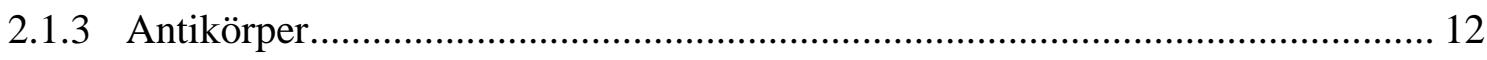

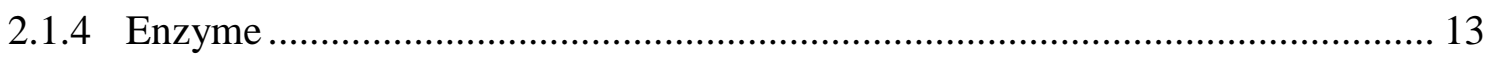

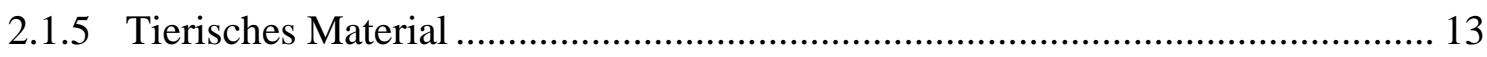

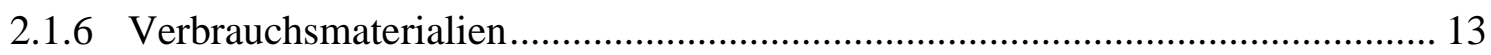

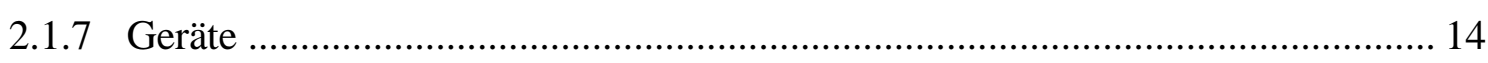

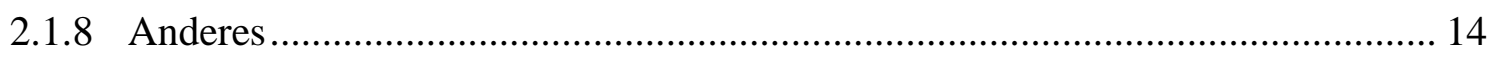

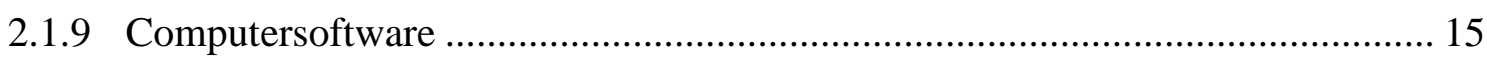

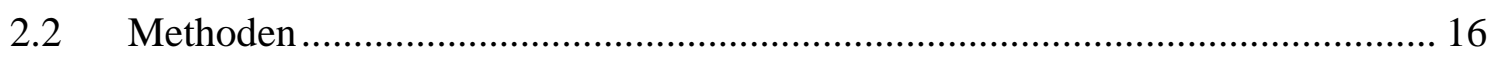

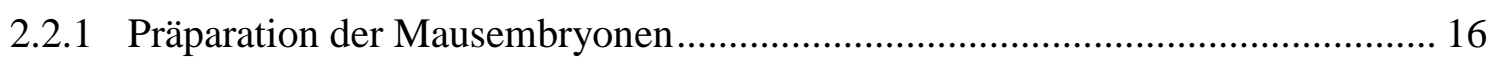

2.2.2 Genotypisierung der Embryonen mittels PCR …………………………........ 17

2.2.3 Fixierung, Einbettung und Schnittanfertigung …………............................... 18

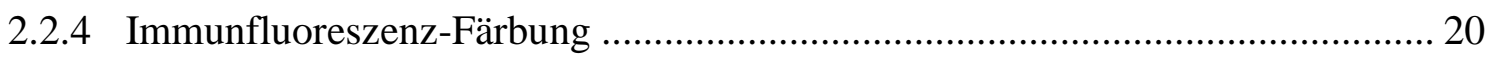

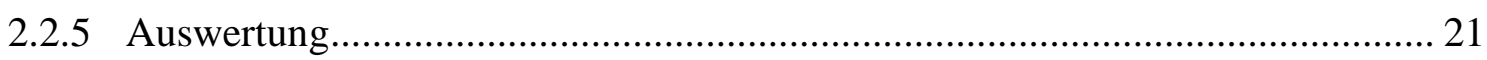




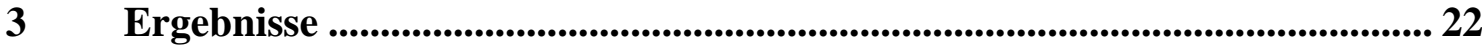

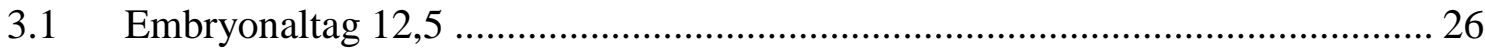

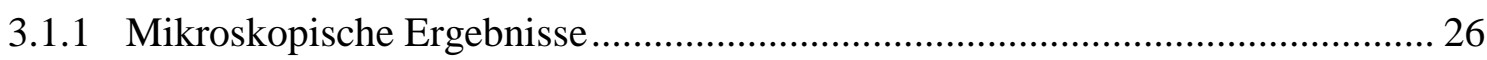

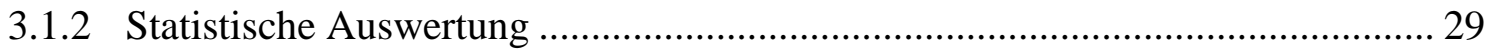

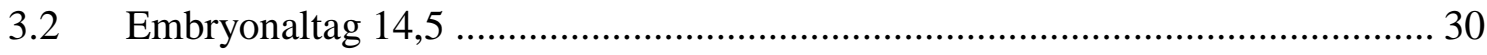

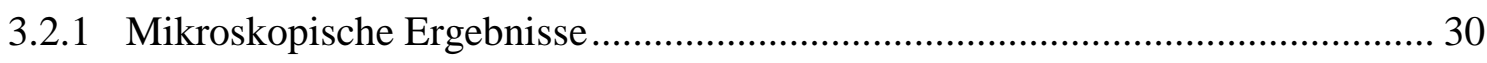

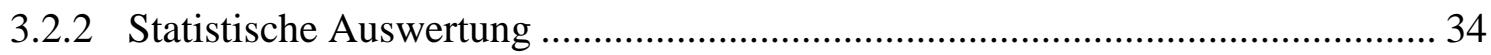

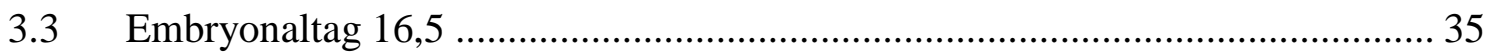

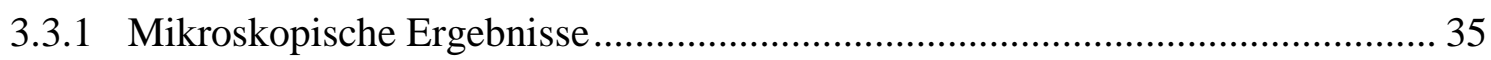

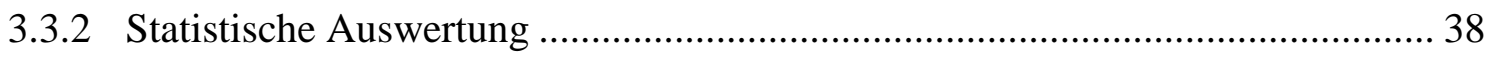

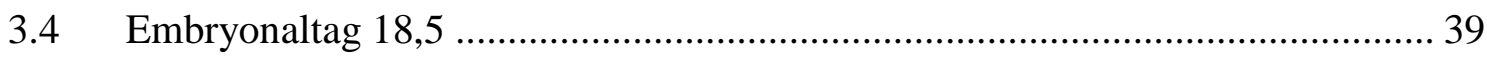

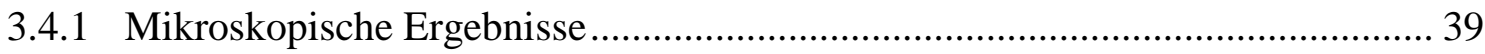

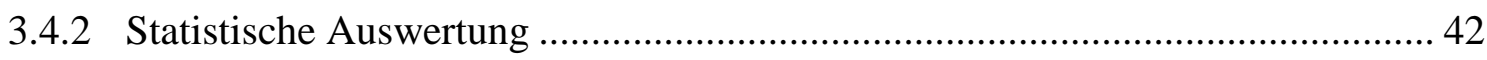

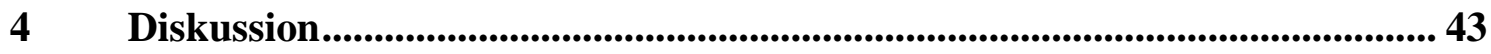

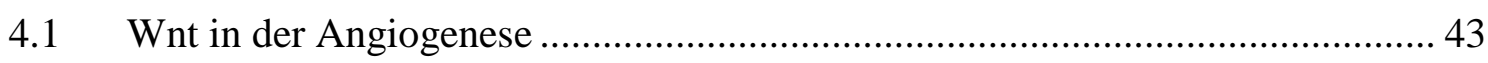

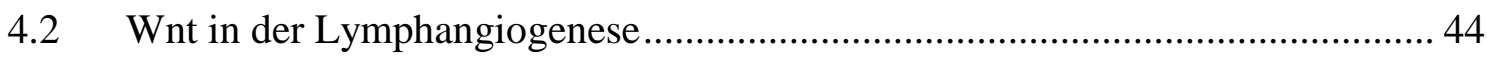

4.3 Andere Mitglieder der Wnt-Genfamilie ......................................................... 44

4.4 Proliferation versus Morphogenese ............................................................ 45

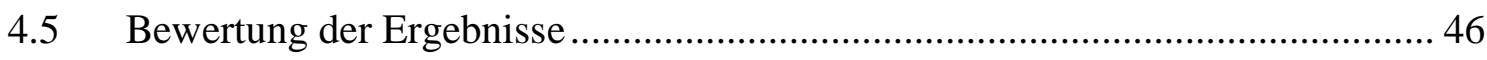

$5 \quad$ Zusammenfassung ................................................................................................... 47

6 Literaturverzeichnis ................................................................................... 49 


\section{Abbildungsverzeichnis}

Abb. 1: Entwicklung der Lymphgefäße aus Venen. Vereinfachte Darstellung................ 3

Abb. 2: Makroskopische Darstellung von Embryonen an Embryonaltag 14,5 ............... 5

Abb. 3: Wnt signaling pathways (Niehrs 2012). ......................................................... 7

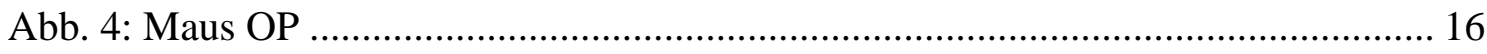

Abb. 5: Gelelektrophorese, gefärbt mit Ethidiumbromid............................................. 18

Abb. 6: Auswertung anhand eines Beispiels ............................................................. 23

Abb. 7: Übersicht der Lymphsäcke von ED-12,5-Embryonen...................................... 26

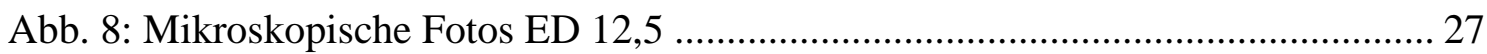

Abb. 9: Mikroskopische Fotos eines homozygoten ko-Embryos ED 12,5 ................... 28

Abb. 10: Graphische Darstellung der Ergebnisse für ED 12,5 …............................... 29

Abb. 11: Übersicht der Hautpräparate der Embryonen ED 14,5 ................................ 30

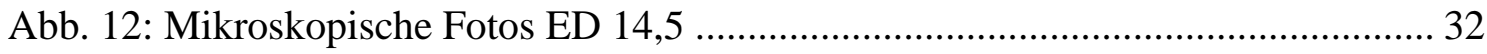

Abb. 13: Mikroskopische Fotos eines homozygoten ko-Embryos ED 14,5 .................. 33

Abb. 14: Graphische Darstellung der Ergebnisse für ED 14,5 ................................... 34

Abb. 15: Übersicht der Hautpräparate der Embryonen ED 16,5 .................................. 35

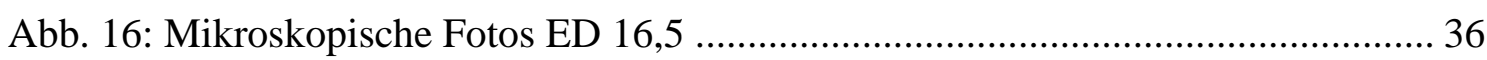

Abb. 17: Mikroskopische Fotos eines homozygoten ko-Embryos ED 16,5 ................. 37

Abb. 18: Graphische Darstellung der Ergebnisse für ED 16,5 .................................. 38

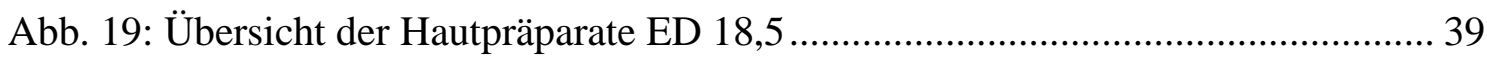

Abb. 20: Mikroskopische Fotos ED 18,5, Wildtyp und heterozygoter ko ...................... 40

Abb. 21: Mikroskopische Fotos eines homozygoten ko-Embryos ED 18,5 .................. 41

Abb. 22: Graphische Darstellung der Ergebnisse für ED 18,5 …............................. 42

\section{Tabellenverzeichnis}

Tabelle 1: Primärantikörper für Immunhistologische Untersuchungen..............................12

Tabelle 2: Gekoppelte Sekundärantikörper für Immunhistologische Untersuchungen ... 13

Tabelle 3: Übersicht der untersuchten Embryos 


\section{Abkürzungsverzeichnis}

$\alpha \quad$ anti

Abb. Abbildung

bp Basenpaare

BSA Bovines Serumalbumin

CD 31, $34 \quad$ Cluster of Differentiation 31 or 34

Celsr1 Cadherin Egf Lag Seven-Pass G-Type Receptor 1

Dapi 4',6-Diamidin-2-phenylindoldihydrochlorid

DNA Desoxyribonukleinsäure

ED Embryonal Day

et al. et alii

het heterozygot

ko knock-out

KPP Kaliumphosphat-Puffer

LEC Lymphendothelzellen

LRP 5,6 Low Density Lipoprotein Receptor-Related Protein 5 or 6

Lyve-1 Lymphatic Vessel Endothelial Hyaluronan Receptor 1

PBS Phosphate-Buffered Saline

PCP Planar Cell Polarity

PCR Polymerase-Ketten-Reaktion

Prox $1 \quad$ Prospero Homeobox Protein 1

Ror1 Receptor Tyrosine Kinase-like Orphan Receptor 1

Ror2 Receptor Tyrosine Kinase-like Orphan Receptor 2

VEGF-A, -C Vascular Endothelial Growth Factor A or C

VEGFR-2, -3 Vascular Endothelial Growth Factor Receptor-2, -3

Wnt5a Wingless-Type MMTV Integration Site Family, Member $5 a$ 


\section{Einleitung}

Das lymphatische System gliedert sich in die primären und sekundären lymphatischen Organe und das Lymphgefäßsystem. Eine wichtige Aufgabe ist die Immunabwehr. Die Lymphozyten können in den sekundären lymphatischen Organen, z.B. Lymphknoten oder Tonsillen, eine spezifische Immunantwort hervorrufen. Eine der wichtigsten Aufgaben des Lymphgefäßsystems ist die Regulierung des Wasserhaushaltes und die Aufrechterhaltung der Flüssigkeitshomöostase sowie die Zirkulation von Leukozyten. Zudem ist es involviert in viele wichtige pathologische Prozesse wie die Tumormetastasierung entlang der Lymphgefäße oder die Entstehung von Lymphödemen und Lymphangiomen. Eine deregulierte embryonale Lymphangiogenese kann zu Hyperplasie, Hypoplasie und Fehlbildungen der Lymphgefäße führen und ist somit die Ursache für primäre Lymphödeme (Tammela und Alitalo 2010; Wilting et al. 2005; Connell et al. 2008).

\subsection{Aufbau und Funktion des Lymphgefäßsystems}

Die Lymphkapillaren enden „blind“ in der Peripherie. Sie sammeln sich zu größeren Lymphkollektoren, drainieren Gewebeflüssigkeit und münden im Venenwinkel in die Jugularvene, wo die Lymphflüssigkeit ins Blut gelangt. Auch resorbierte Fette aus dem Darm gelangen so in den Blutkreislauf. Entlang der Lymphgefäße befinden sich zahlreiche Lymphknoten, in denen die Lymphe gefiltert wird. Dort können Fremdpartikel auf Antigen-präsentierenden Zellen eine spezifische Immunantwort initiieren. Lymphgefäße finden sich in der Haut und in den meisten inneren Organen außer dem ZNS (zentrales Nervensystem), dem Knochenmark und in nicht vaskularisierten Geweben wie Kornea, Knorpel und Epidermis (Alitalo et al. 2005) und auch nicht in der Zahnpulpa (Lohrberg und Wilting 2016).

Die Lymphflüssigkeit besteht zum größten Teil aus interstitieller Flüssigkeit, aber auch Lipiden, Proteinen und Ionen. Des Weiteren enthält sie Zellen wie Leukozyten oder Lymphozyten. Durch erhöhten Gewebedruck öffnen sich kleine inter-endotheliale Klappen in der Wand der Lymphgefäße und interstitielle Flüssigkeit, Makromoleküle und Zellen können in die Lymphkapillaren eintreten (Casley-Smith 1980; Baluk et al. 2007). Sobald dies geschehen ist, erhöht sich der Druck in den Lymphkapillaren und die 
Klappen schließen sich wieder. Außerdem fehlt es den Lymphkapillaren an einer kontinuierlichen Basallamina und Perizyten.

Lymphkapillaren sind dünnwandige, relativ große Gefäße mit nur einer Schicht Endothelzellen. Die Lymphe fließt dann in die Lymphkollektoren. Diese hingegen haben eine Muskelzellschicht aus glatter Muskulatur, eine Basalmembran und Taschenklappen. Die Muskelschicht trägt durch ihre peristaltische Kontraktilität, zusätzlich zur skelettalen Muskelaktivität und arterieller Pulsation, zur Lymphbewegung bei. Die Taschenklappen sollen einen Rückfluss verhindern (Alitalo et al. 2005; Leak 1971; Rasmussen et al. 2010).

Schließlich fließt die Lymphe aus der unteren Körperregion und dem oberen linken Körperquadranten in den Ductus thoracicus. Dieser endet im linken Venenwinkel zwischen Vena subclavia sinistra und Vena jugularis interna sinistra. Die Lymphe aus dem oberen rechten Körperquadranten wird über den Ductus lymphaticus dexter drainiert. Dieser mündet in den rechten Venenwinkel zwischen Vena jugularis interna dextra und Vena subclavia dextra. Auf diese Weise werden bis zu vier Liter Lymphflüssigkeit täglich in den Blutkreislauf zurückgeführt.

\subsection{Entwicklung des Lymphgefäßsystems}

Das Lymphgefäßsystem entwickelt sich erst nach dem Blutgefäßsystem und da sich Lymphgefäße meist in unmittelbarer Nähe zu Blutgefäßen befinden, fungieren diese wahrscheinlich als Wegweiser für die Entwicklung. 1902 veröffentlichte Florence Sabin die anerkannteste Theorie über den Ursprung der Lymphgefäße: Lymphsäcke entstehen aus einigen bestimmten Venenabschnitten bzw. deren Endothel. Von den Lymphsäcken ausgehend, sprossen dann die Lymphgefäße in das Gewebe und in die Organe.

Prox1 (Prospero Homeobox Protein 1) wurde als spezifischer Marker für Lymphendothel gefunden. Die Inaktivierung von Prox1 in Mäusen zeigte, dass die Aktivität des Gens in den Endothelzellen der embryonalen Venen wichtig für die Lymphangiogenese ist (Oliver und Harvey 2002). Die Lymphangiogenese wird durch komplexe Wechselwirkungen von Transkriptionsfaktoren wie Sox18 und Prox1 sowie Wachstumsfaktoren und ihren Rezeptoren wie VEGF-C (Vascular Endothelial Growth Factor C) und VEGFR3 (Vascular Endothelial Growth Factor Receptor 3) gesteuert (Tammela und Alitalo 2010; Wilting et al. 1999). Die früheste Phase der Entwicklung 
bzw. Spezifikation der Lymphendothelzellen wird von Sox18 und Prox1 kontrolliert (Francois et al. 2008) und erfolgt in bestimmten Segmenten der Kardinalvenen. Der Transkriptionsfaktor Prox1 und der VEGF-C sind wichtig für das Wachstum der Lymphgefäße während der embryonalen Entwicklung (Saharinen et al. 2004).

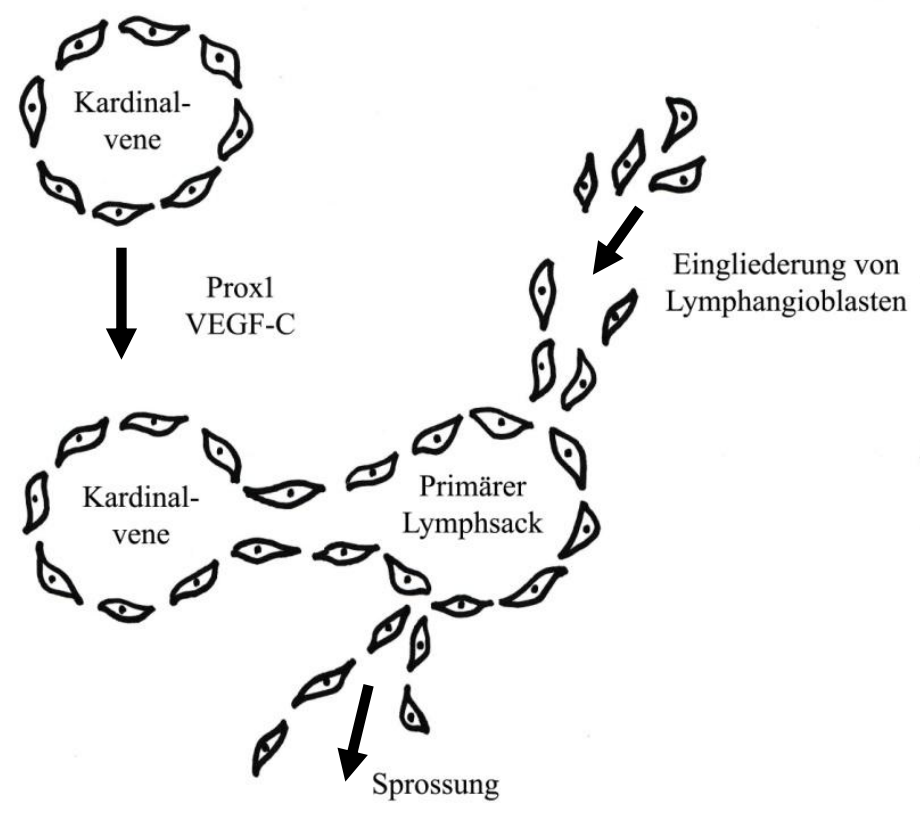

Abb. 1: Entwicklung der Lymphgefäße aus Venen. Vereinfachte Darstellung.

Hauptsächlich erfolgt die Bildung durch Sprossen aus den Venen, aber auch durch Eingliederung von Lymphangioblasten (siehe Abb. 1). Darauf folgt zusätzlich eine mesenchymale Phase der Lymphangiogenese, die am deutlichsten mittels Life Cell Imaging bei Zebrafischen gezeigt wurde (Yaniv et al. 2006), aber auch bei Küken und Mäusen zu finden ist (Pollmann et al. 2014; Schneider et al. 1999).

\subsection{Entwicklung der Blutgefäße}

Blutkapillaren werden in allen Geweben für die Diffusion bzw. den Austausch von Nährstoffen und Stoffwechselprodukten benötigt. Hämangioblasten, Vorläuferzellen aus dem Mesoderm, bilden primäre Blutinseln, aus denen sich die äußeren Zellen zu Endothelzellen und die inneren Zellen zu hämatopoetischen Zellen differenzieren. Aussprossende Endothelzellen dieser Blutinseln verbinden sich und bilden einen primären Plexus. Der Vorgang wird Vaskulogenese genannt. Darauf folgt die Angiogenese, die das Wachstum und die Umgestaltung des primären Gefäßnetzes 
beschreibt. Dies geschieht durch Sprossung der Endothelzellen, Teilung größerer Gefäße und Vergrößerung von Gefäßen. Dieser dynamische Prozess wird von Wachstumsfaktoren gesteuert. Er beinhaltet die Differenzierung von mesodermalen Stammzellen zu Angioblasten und die Wachstumsfaktor-gesteuerte Migration der Angioblasten zur Formung der Blutinseln, wo die Angioblasten dann die Endothelzellen bilden (Adair und Montani 2010). Einer der wichtigsten Wachstumsfaktoren für die Entwicklung der Blutgefäße ist der VEGF-A, der ausschließlich blutgefäßbildende Wirkung besitzt.

\subsection{Wnt5a}

\subsubsection{Das Gen}

Wnt5a (Wingless-Type MMTV Integration Site Family, Member 5a) ist ein sezerniertes Glykoprotein der Wnt-Genfamilie. Wnt5a ist im Gegensatz zu den anderen Mitgliedern seiner Familie (zum Beispiel Wnt1, 6, 7a, 7b, 8b, 11) in deutlich höherer Konzentration in Lymphendothelzellen $\mathrm{zu}$ finden als in Blutendothelzellen. Es gehört $\mathrm{zu}$ den Regulatoren von Proliferation, Migration, Differenzierung und Apoptose bei der Embryonalentwicklung (Logan und Nusse 2004). Lokalisiert ist es in Extremitäten, Genitalien, Gesicht und Außenohr. Homozygote Wnt5a knock-out (ko)-Mäuse, bei denen dieses Gen fehlt, entwickeln sich abnormal und sterben kurz nach der Geburt aufgrund multipler Defekte (Yamaguchi et al. 1999). Der transgene homozygote koEmbryo hat verkürzte Extremitäten sowie auch einen verkümmerten Schwanz (siehe Abb. 2). Des Weiteren ist der Unterkiefer stark unterentwickelt und eine Schnauze ist nicht zu erkennen (Buttler et al. 2013). Er zeigt außerdem Kleinwüchsigkeit, Dysplasie der Lunge und der Genitalien sowie Ventrikelseptumdefekte (Oishi et al. 2003). Auch hat Wnt5a einen Einfluss auf die Blutgefäßentwicklung (Cirone et al. 2008) und die Lymphangiogenese der epifaszialen Lymphgefäße. Die oberflächlichen Lymphkollektoren sind nicht regelgerecht ausgebildet und die initialen Lymphgefäße der Dermis formen keine regelmäßigen Netzwerke, sondern zeigen eine veränderte Morphologie im Gegensatz zu Wildtyp (wt) und heterozygoten ko-Mäusen (Buttler et al. 2013). 


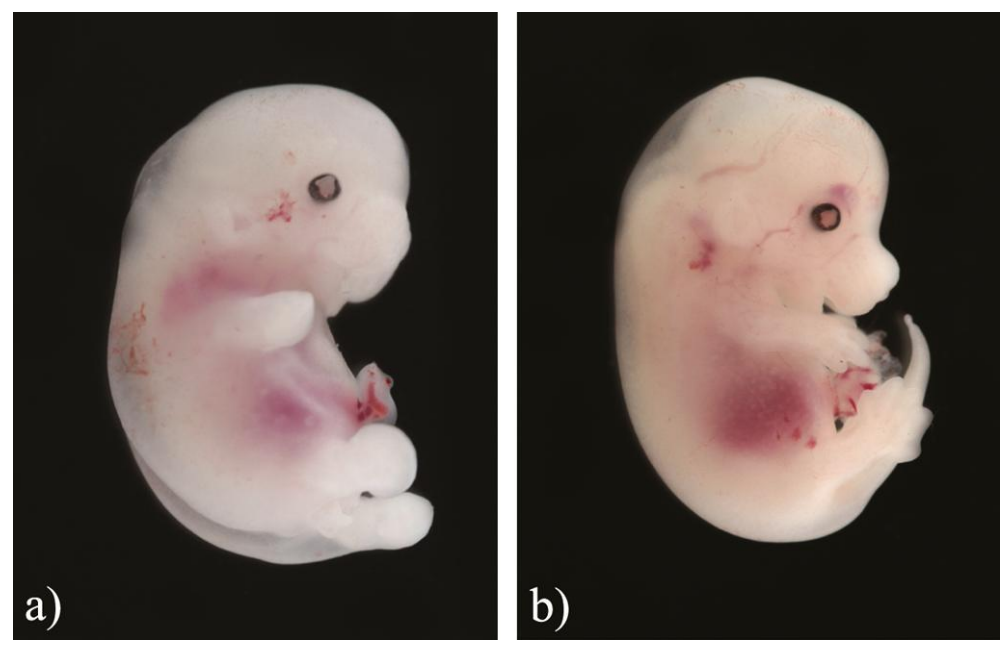

Abb. 2: Makroskopische Darstellung von Embryonen an Embryonaltag 14,5

a) Homozygoter knock-out-Embryo; b) Wildtyp-Embryo. Beim knock-out-Embryo sind deutlich zu erkennen die verkürzten Extremitäten und der verkümmerte Schwanz, auch eine Schnauze ist nicht zu erkennen aufgrund der Unterentwicklung des Unterkiefers.

Beim Menschen führen dominante Mutationen des Gens WNT5A und rezessive Mutationen des ROR2 (Receptor Tyrosine Kinase-like Orphan Receptor 2)-Gens zum Robinow-Syndrom (Bacino 1993; Person et al. 2010). Diese Patienten besitzen mehrere angeborene Defekte, einschließlich Defekten des kardiovaskulären Systems, die auch bei homozygoten Wnt5a- und Ror2-ko-Mäusen ähnlich zu beobachten sind (Oishi et al. 2003).

Wahrscheinlich agiert Wnt zusammen mit anderen Signaltransduktionswegen wie Notch oder TGFß (Transforming Growth Factor B) bei der Modulation von Gefäßentwicklung und endothelialer Spezifikation. Dabei kann ein Wnt-Protein oder sein Rezeptor unterschiedliche Reaktionen in den Endothelzellen induzieren. Es kommt dabei offensichtlich auf den lokalen Kontext an, wie z. B. die Aktivierung durch Wachstumsfaktoren, Sauerstoffsättigung, Induktion von Permeabilität, Expression verschiedener Transkriptionsfaktoren etc. (Dejana 2010).

\subsubsection{Wnt5a-Signaltransduktionsweg}

Der Wnt5a-Signalweg ist komplex. Es gibt mindestens drei Signalwege, in denen verschiedene Rezeptoren und Ko-Rezeptoren eine Rolle spielen. Das sind der PCP Signalweg (Planar Cell Polarity), der ß-Catenin-abhängige Signalweg sowie der $\mathrm{Wnt} / \mathrm{Ca}^{+}$Signalweg. 
Der B-Catenin-abhängige Signalweg ist der kanonische (übliche) Signalweg, der am besten verstanden und am meisten untersucht ist (siehe Abb. 3b). Die Wnt-Proteine binden an Frizzled-Rezeptoren und bilden einen Komplex mit LRP-5 oder -6 (Low Density Lipoprotein Receptor-Related Protein 5 oder 6). Dieser Prozess an der Zelloberfläche aktiviert intrazellulär die Proteine Dishevelled und Axin, sodass sich BCatenin sowohl im Zytoplasma als auch im Zellkern ansammelt. Der Komplex inhibiert also den Abbau von B-Catenin im Zytoplasma und stabilisiert die Konzentration von BCatenin. Im Zellkern interagieren $\beta$-Catenin und TCF (T-cell factor), und über Transkriptionsfaktoren werden daraufhin verschiedene Gene transkribiert. Fehlt das Wnt5a-Protein, wird über einen Kontrollkomplex aus mehreren Proteinen zytoplasmatisches ß-Catenin abgebaut, und es kommt nicht zur Transkription der Gene. ß-Catenin kann auch an Cadherin durch Zell-zu-Zell-Kontakte binden und stabilisiert so die Interaktion mit dem Zytoskelett. Diese Bindung von Cadherin zu ß-Catenin in einem Komplex kann so das Wnt-Signaling limitieren (MacDonald et al. 2009; Dejana 2010).

Der häufigste Weg ist allerdings nicht dieser, sondern wahrscheinlich einer der nicht kanonischen Signalwege, die außerdem $\beta$-Catenin-unabhängig sind. Diese sind der PCP-Signalweg und der Wnt/Calcium-Signalweg, die über die Transmenbranrezeptoren Ror1, Ror2 und Ryk (Receptor-like Tyrosine Kinase) vermittelt werden (Fukuda et al. 2008; Keeble et al. 2006; Mikels and Nusse 2006). Der Wnt/Calcium-Signalweg wird aktiviert, wenn Wnt an spezifische Frizzled-Rezeptoren bindet, welche die Phospholipase $\mathrm{C}$ aktivieren und die intrazellulären Calcium-Konzentration steigern (siehe Abb. 3c) (Dejana 2010). Diese B-Catenin-unabhängigen Signalwege können den kanonischen Signalweg inhibieren. Die Regulation scheint abhängig zu sein von der Verfügbarkeit und dem Aktivitätsstatus der Liganden und Rezeptoren sowie den an den Mechanismen beteiligten Zelltypen (van Amerongen et al. 2008). 


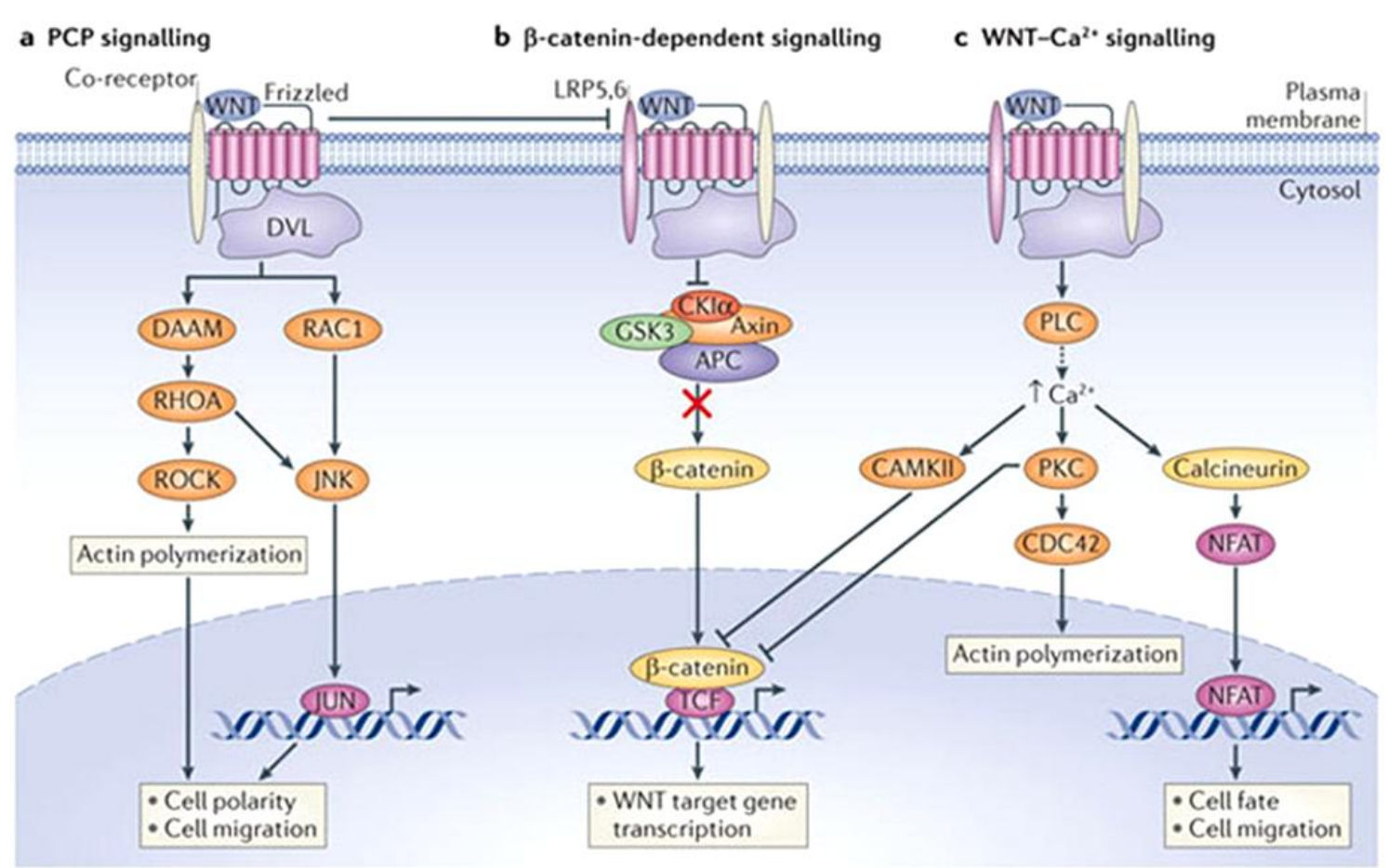

Abb. 3: Wnt signaling pathways (aus: Niehrs 2012, Copyright Nr.: 4185950030514)

a) PCP Signalweg; b) ß-Catenin-abhängiger Signalweg; c) Wnt/Ca ${ }^{+}$Signalweg.

Es ist noch offen, welcher Wnt-Ligand an welchen Frizzled-Rezeptor bindet, welcher Rezeptor dadurch aktiviert wird und ob alle Frizzled-Rezeptoren den ß-Catenin abhängigen oder unabhängigen Signalweg auslösen. Verschiedene Wnt-Rezeptoren sind verantwortlich für die Aktivierung des einen oder anderen Signalweges, wobei wahrscheinlich einige Rezeptoren sowohl den kanonischen als auch die nicht kanonischen Signalwege aktivieren können. Wenn Wnt verschiedene Signalwege beeinflusst und von diesen sowie dessen Konditionen beeinflusst wird, stellt sich die Frage, ob vaskuläre Patholgien auf Wnt zurück zu führen sind (Dejana 2010).

Der Wnt-Signalweg spielt eine Rolle bei der Regulation des Wachstums der Endothelzellen und der Regulation der Angiogenese. Die Aktivierung des Wnt/Calcium-Signalweges induziert eine Zellproliferation und inhibiert die Apoptose in Endothelzellen in vitro. In vivo wird eine pro-angiogene Aktivität erwartet (Goodwin et al. 2007; Masckauchan et al. 2006). Der PCP Signalweg hingegen spielt eine Rolle in der Gefäßmorphologie (Cirone et al. 2008) und bei der Regulation von Adhäsionsverbindungen und der gerichteten Zellreorganisation während der vaskulären Entwicklung. Dort ist Celsr1 (Cadherin Egf Lag Seven-Pass G-Type Receptor 1) wichtig. Celsr1 defiziente Mäuse zeigen eine Aplasie der Gefäßklappen aufgrund des 
Versagens von Endothelzellen sich zu reorganisieren und eine senkrechte Orientierung an den Klappenbildungsstellen einzugehen (Tatin et al. 2013).

\subsection{Molekulare Strukturen}

\subsubsection{VEGF-C}

Der VEGF-C gehört zur Vascular Endothelial Growth Factor (VEGF)-Familie, zu der noch vier weitere Faktoren zählen: VEGF-A, -B, -C und der Placenta Growth Factor (PIGF) (Neufeld et al. 1999). Allerdings spielen nur VEGF-C und -D mit ihren Rezeptoren VEGFR-2 und -3 eine wichtige Rolle bei der Lymphangiogenese. So wurde eine hohe Expression von VEGF-C insbesondere in den Regionen gefunden, wo Lymphgefäßentwicklung eine Rolle spielt, zum Beispiel in der Jugularregion von Embryonen (Kukk et al. 1996). VEGF-C und -D sind außerdem beteiligt an einer entzündungsbedingten Lymphangiogenese, an Wundheilung und Tumormetastasierung (Saharinen et al. 2004).

Die VEGF-Rezeptoren befinden sich auf Lymphendothelzellen. Diese Gene sind identifiziert worden und sie $\mathrm{zu}$ modifizieren oder auszuschalten, eröffnet neue Möglichkeiten, die Entwicklung und Funktion der Lymphgefäße zu verstehen und neue Behandlungen für die damit assoziierten Krankheiten zu finden (Takahashi et al. 2004).

\subsubsection{Marker von Lymphendothelzellen}

Es existieren Marker, mit denen Lymphendothelzellen identifiziert werden können. Als erstes ist Prox $1 \mathrm{zu}$ nennen. Prox1 ist ein Homöobox Transkriptionsfaktor, der stark exprimiert wird im Lymphendothel von Menschen, Mäusen und Vögeln. Er befindet sich im Zellkern. Prox1 ist ein konstitutiver Marker von Lymphendothelzellen. Endothelzellen von Blutgefäßen, z. B. in Hämangiomen, exprimieren CD31 und CD34 (Cluster of Differentiation 31 und 34), nicht aber Prox1. In Lymphangiomen exprimieren die Lymphendothelzellen Prox1, CD31 und VEGFR-3 und nur selten CD34. Also ist Prox1 ein zuverlässiger Marker für Lymphendothelzellen sowohl im normalen als auch im pathologischen menschlichen Gewebe, koexprimiert mit VEGFR-3 und CD31. VEGFR-3 ist einzeln allerdings ein wenig zuverlässiger Marker, da Ausnahmen von den normalen Expressionsmustern in pathologischem Gewebe gefunden wurden (Wilting et al. 2002). Daneben wird Prox1 auch schwach in 
Hepatozyten, Kardiomyozyten und neuronalen Zellen exprimiert (RodriguezNiedenführ et al. 2001). Bei Mäusen, bei denen das Gen ausgeschaltet worden ist, wachsen keine Lymphgefäße, wobei Vaskulogenese und Angiogenese des Blutgefäßsystems nicht betroffen sind. Dies bedeutet, dass Prox1 ein spezifischer Regulator der Entwicklung des lymphatischen Systems ist und sich Blutgefäßsystem und Lymphgefäßsystem unabhängig voneinander weiterentwickeln (Wigle und Oliver 1999).

Ein weiterer wichtiger Marker für Lymphendothelzellen ist der integrale MembranHyaluronan-Rezeptor Lyve-1 (Lymphatic Vessel Endothelial Hyaluronan-Receptor 1). Dieses transmembrane Glykoprotein wird stark auf den Lymphendothelzellen der initialen Lymphgefäße exprimiert. Allerdings wird er nicht ausschließlich dort exprimiert, sondern findet sich auch in verstreuten mesenchymalen Zellen und in spezifischen Blutendothelzellen in der Leber und der Milz und in hochendothelialen Venolen der lymphatischen Organe (Sleeman et al. 2001; Wrobel et al. 2005). Er ist wahrscheinlich am Transport von Hyaluronsäure durch das Lymphendothel in das Lymphsystem beteiligt (Prevo et al. 2001). Bei Mäusen, denen Lyve-1 fehlt, hat man allerdings keine Beeinträchtigung der Entwicklung und Funktion von Lymphgefäßen festgestellt (Gale et al. 2007).

Ein dritter Marker für Lymphendothelzellen ist Podoplanin, welches auf Lymphendothelzellen, aber nicht auf Blutendothelzellen zu finden ist. Dieses integrale Membranprotein wird aber von verschiedenen Zellen wie z.B. Osteoblasten, Epithelzellen des Plexus choroideus und Pneumozyten Typ I exprimiert (Sleeman et al. 2001). Mäuse, denen Podoplanin fehlt, sterben aufgrund respiratorischer Defekte bei der Geburt. Die Blutgefäße sind normal entwickelt, im Gegensatz zu den Lymphgefäßen, die Defekte aufweisen. Diese Defekte sind assoziiert mit reduziertem Lymphtransport, angeborenen Lymphödemen und dilatierten Lymphgefäßen (Schacht et al. 2003). 


\subsection{Zielsetzung}

Die Entwicklung der Lymphgefäße und die bei der Lymphangiogenese beteiligten Gene, zum Beispiel Wnt5a, Prox1, Sox18 oder VEGF-C, sind bis jetzt wenig untersucht worden. In meiner Arbeit soll es nun um das Gen Wnt5a gehen. In der Arbeit von Buttler et al. (2013) wurden Mausembryonen des Embryonaltages (ED) 18,5 im Hinblick auf die Frage untersucht, inwiefern das Gen Wnt5a wichtig für Lymphangiogenese sei. Die Ergebnisse zeigen, dass das Fehlen des Gens einen Einfluss auf die Lymphangiogenese hat. Die Lymphgefäße der homozygoten knock-out (ko)Embryonen, in denen das Gen vollständig ausgeschaltet wurde, schienen zystisch vergrößert, aber gleichzeitig gab es auch weniger Gefäße. Daraus wurde geschlossen, dass Wnt5a die Bildung eines verzweigten Netzwerks von Lymphkapillaren und die Bildung der Kollektoren steuert, nicht aber die Proliferation beeinflusst. In den koMausembryonen fand man die Hautlymphgefäße in einem unreifen, wenig differenziertem Stadium.

Ziel meiner Arbeit ist es nun herauszufinden, ob die Hypothese im Hinblick auf die Proliferation der Lymphendothelzellen bestätigt werden kann oder nicht. Dazu untersuche ich nicht nur Embryonen des Embryonaltags 18,5, sondern zusätzlich auch Embryonen in den Stadien ED12,5, ED14,5 und ED16,5. Des Weiteren untersuche ich jeden Genotyp, also Wildtyp (wt), heterozygote ko- (het) und homozygote koEmbryonen, einzeln und vergleiche sie miteinander.

Mit Lymphendothelmarkern und Proliferationsmarkern in einer immunhistologischen Untersuchung kann eine gezielte Aussage über die Anzahl der proliferierenden Lymphendothelzellen getätigt werden. Der Vergleich der verschiedenen Genotypen gibt Aufschluss darüber, ob Wnt5a die Proliferation der Lymphendothelzellen in Mausembryonen steuert. 


\section{$2 \quad$ Material und Methoden}

\subsection{Material}

\subsubsection{Chemikalien}

Zur Herstellung der in 2.1.2 angegebenen Lösungen und Puffer wurden folgende Chemikalien verwendet.

Agarose

BSA (Bovines Serumalbumin)

di-Kaliumhydrogenphosphat

di-Natriumhydrogenphosphat

Ethidiumbromid

Kaliumdihydrogenphosphat

Natriumchlorid

Paraformaldehyd

PBS (Phosphate- Buffered Saline)

Saccharose

Trizol

Wasser, destilliert
Starlab, Hamburg

AppliChemPanReac, Darmstadt

Roth, Karlsruhe

Merck, Darmstadt

Roth, Karlsruhe

Merck, Darmstadt

Roth, Karlsruhe

Sigma-Aldrich, München

Cambrex, Taufkirchen

Merck, Darmstadt

Invitrogen, Karlsruhe

Universität Göttingen 


\subsubsection{Lösungen und Puffer}

Die Lösungen und Puffer wurden, wenn nicht anders angegeben, mit destilliertem Wasser angesetzt.

BSA-Lösung

$\mathrm{KPP}(\mathrm{pH} 7,4-7,8)$

Paraformaldehydlösung

PBS (pH 7,2)

Saccharose-Lösung
$1 \%$ BSA; 1x PBS

\section{$0,2 \quad \mathrm{M} \quad \mathrm{KH}_{2} \mathrm{PO}_{4} ; \quad 0,2 \quad \mathrm{M} \quad \mathrm{K}_{2} \mathrm{HPO}_{4} ;$}

Gebrauchslösung 0,1 M

4\% Paraformaldehyd; 1x PBS

0,01 M; 2,7 M Natriumchlorid; 0,2 M Di-

Natriumhydrogenphosphat; 0,04 M

Kaliumdihydrogenphosphat;

Gebrauchslösung $1 \mathrm{mM}(1 \mathrm{x})$

10\% Saccharose; 0,1 M KPP

30\% Saccharose; 0,1 M KPP

\subsubsection{Antikörper}

Die Verdünnungen der Antikörper erfolgten entsprechend mit BSA-Lösung

Tabelle 1: Primärantikörper für Immunhistologische Untersuchungen

\begin{tabular}{|llll|}
\hline Antikörper & Spezies & Verdünnung & Hersteller \\
\hline$\alpha$ (anti)-Maus-Ki-67 & Ratte & $1: 100$ & \\
& & & Dako, Hamburg \\
$\alpha$-Mensch-Prox1 & Kaninchen & $1: 500$ & $\begin{array}{l}\text { ReliaTech, } \\
\text { Wolfenbüttel }\end{array}$ \\
\hline
\end{tabular}


Tabelle 2: Gekoppelte Sekundärantikörper für immunhistologische Untersuchungen

\begin{tabular}{|c|c|c|c|}
\hline $\begin{array}{l}\text { Gekoppelte } \\
\text { Antikörper }\end{array}$ & Spezies & Verdünnung & Hersteller \\
\hline$\alpha$-Ratte-Alexa 488 & Ziege & $1: 200$ & $\begin{array}{l}\text { MobiTech, } \\
\text { Göttingen }\end{array}$ \\
\hline $\begin{array}{l}\alpha \text {-Kaninchen-Alexa } \\
594\end{array}$ & Ziege & $1: 200$ & $\begin{array}{l}\text { MobiTech, } \\
\text { Göttingen }\end{array}$ \\
\hline
\end{tabular}

\subsubsection{Enzyme}

HotStarTaq DNA-Polymerase Qiagen, Hilden

\subsubsection{Tierisches Material}

Wnt5 $\mathrm{a}^{\mathrm{tm} 1 \mathrm{Amc}}$ B6-Mäuse wurden bei The Jackson Laboratory (Bar Harbor, Maine, USA) gekauft und in der Zentralen Tierexperimentellen Einrichtung der UMG, Göttingen, weiter gezüchtet. Die Mausembryonen ED 12,5, 14,5, 16,5 und 18,5 wurden wie in 2.2.1 beschrieben dem Muttertier entnommen.

\subsubsection{Verbrauchsmaterialien}

Deckgläser

Reaktionsgefäße $(0,5 \mathrm{ml} ; 1,5 \mathrm{ml})$

Fluoromount-G

Objektträger mit Mattrand

Superfrost Objektträger
Menzel, Braunschweig

Sarstedt, Nümbrecht

Southern Biotech, Birmingham,

USA

Waldemar Knittel, Braunschweig

Menzel, Braunschweig 
Tissue Tek O.C.T.

Petrischalen $(10 \mathrm{~cm}, 5 \mathrm{~cm}$ Durchmesser $)$

\subsubsection{Geräte}

Beleuchtung CTR 5000 für Mikroskop

Beleuchtung KL1500LCD

Beleuchtung MTR38

Binokular Leica MZ6

Fluoreszenzmikroskop DM5000B

Geldokumentationsapparatur

Gelkammer für Agarosegele H5

Kamera DC300FX (Mikroskop)

Kryotom CM3050S

Spannungsgerät für Gele Consort E455

Vortex Heidolph Relax top

Zentrifuge 5415R

\subsubsection{Anderes}

4',6-Diamidin-2-phenylindoldihydrochlorid

Dapi-Verdünnung: 1:10.000

Einfrierbox

Federscheren

Feuchte Kammer

Mikrolöffel
Sakura Finetek Europe,

Zoeterwoude, Niederlanden

Greiner, Solingen

Leica, Wetzlar

Leica, Wetzlar

Leica, Wetzlar

Leica, Wetzlar

Leica, Wetzlar

Intas, Göttingen

Bethesda Research Laboratories,

Gaithersburg, USA

Leica, Wetzlar

Leica, Wetzlar

LMS Labortechnik, Dossenheim

Oehmen Labortechnik, Essen

Eppendorf, Hamburg

Sigma-Aldrich, München

Nunc, Wiesbaden

Geuder, Heidelberg

Universitätsklinikum Göttingen,

Technik

Roth, Karlsruhe 
Pipetten

Präzisionspinzetten

Siebspatel

\subsubsection{Computersoftware}

Adobe Photoshop 7.0

Axiovision Rel. 4.6

Citavi 5.0

GraphPad Prism 5

ImageJ 1.46r

Microsoft Office Word 2010
Gilson, Limburg-Offheim

Roth, Karlsruhe

Geuder, Heidelberg

Adobe Systems, San José, USA

Carl Zeiss, Jena

Swiss Academic Software,

Wädenswil, Schweiz

GraphPad Sofware, La Jolla, USA

Wayne Rasband, Washington D.C., USA

Microsoft, Redmont, USA 


\subsection{Methoden}

\subsubsection{Präparation der Mausembryonen}

Die trächtigen Mäuse wurden nach $\mathrm{CO}_{2}$-Narkose durch Genickbruch getötet. Danach wurde das Abdomen mit einem Skalpell vertikal eröffnet (siehe Abb. 4) und der Uterus mit den Embryonen aus dem Muttertier herauspräpariert und in kaltes PBS gelegt. Nun konnte der Uterus unter einem Mikroskop mit einer Mikroschere eröffnet werden, und die Embryonen wurden freipräpariert. Dabei war darauf zu achten, dass das Amnion entfernt wurde. Alle Präparationen erfolgten in PBS.

Der nächste Schritt war das Abtrennen des Schwanzes oder, bei zu kurzem Schwanz, einer Extremität des Embryos für eine spätere Genotypisierung mittels PCR.

Embryonen des Entwicklungstages 12,5 wurden im Ganzen benötigt. Bei den Embryonen der Entwicklungstage 16,5 und 18,5 wurden Bauch- und Rückenhäute mit Hilfe von Präzisionspinzetten einzeln vom Embryo abpräpariert. Im Entwicklungsstadium ED 14,5 wurden sowohl ganze Embryonen als auch Hautpräparate vorbereitet. Im Vorfeld war nicht klar, ob ganze Embryonen des Embryonaltags 14,5 mit dem Kryotom geschnitten werden können, weil in diesem Stadium die Verknöcherung beginnt. Es stellte sich dann heraus, dass es möglich war, und so konnten sowohl die ganzen Embryonen als auch die Hautpräparate genutzt werden.

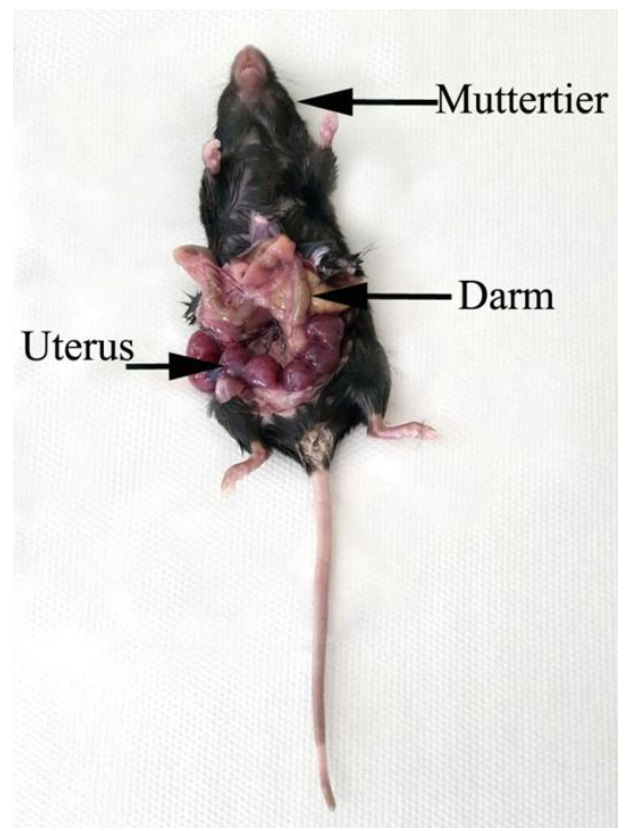

Abb. 4: Maus OP

$\mathrm{Zu}$ sehen ist das Muttertier, dessen Abdomen eröffnet wurde. Der perlschnurartig ausgebildete Uterus mit den Embryonen und der Darm sind zu erkennen. 


\subsubsection{Genotypisierung der Embryonen mittels PCR}

Wnt5 $\mathrm{a}^{\text {tm1Amc }}$ B6-Mäuse (The Jackson Laboratory; Bar Harbor, Maine, USA) wurden in der Tierexperimentellen Einrichtung der UMG weitergezüchtet. Die Muttertiere wurden mir dann zur Verfügung gestellt. Von jedem einzelnen Embryo wurde eine Gewebeprobe entnommen (meist die Schwanzspitze) und einer Genotypisierung zugeführt. Die DNA (Desoxyribonukleinsäure) wurde mit Trizol isoliert und einer Polymerase-Ketten-Reaktion (PCR) zugeführt. Mit Hilfe der PCR ist es möglich, einzelne DNA-Fragmente zu vervielfachen. So konnten die Genvarianten der Mausembryonen bestimmt werden (Abb. 5).

Die Multiplex-PCR erfolgte zyklisch in einem Thermocycler mit jeweils drei Schritten pro Zyklus. Im ersten Schritt wurde die DNA bei einer Temperatur von $94{ }^{\circ} \mathrm{C}$ denaturiert, sodass der Doppelstrang sich teilte. Danach lagerten sich die Oligonukleotide (Primer) bei einer Temperatur von $62{ }^{\circ} \mathrm{C}$ an die spezifischen Bindungsstellen des Einzelstrangs. Im letzten Schritt verlängerte die DNA-Polymerase bei einer Temperatur von $72{ }^{\circ} \mathrm{C}$ die Primer am Einzelstrang in 5'- 3'-Richtung, sodass ein neuer Doppelstrang synthetisiert wurde. Dieser Zyklus wurde 35-mal wiederholt. Die DNA-Fragmente vermehrten sich exponentiell.

Folgende Primer wurden für die PCR benutzt: Wild-type forward, 5'GAG GAG AAG CGC AGT CAA TC3'; mutant forward, 5'GCC AGA GGC CAC TTG TGT AG3' und gemeinsam: reverse, 5'CAT CTC AAC GGC CTC AT3'.

Im Anschluss wurden die Produkte der PCR mittels einer Agarose-Gelelektrophorese analysiert (siehe Abb. 5). 


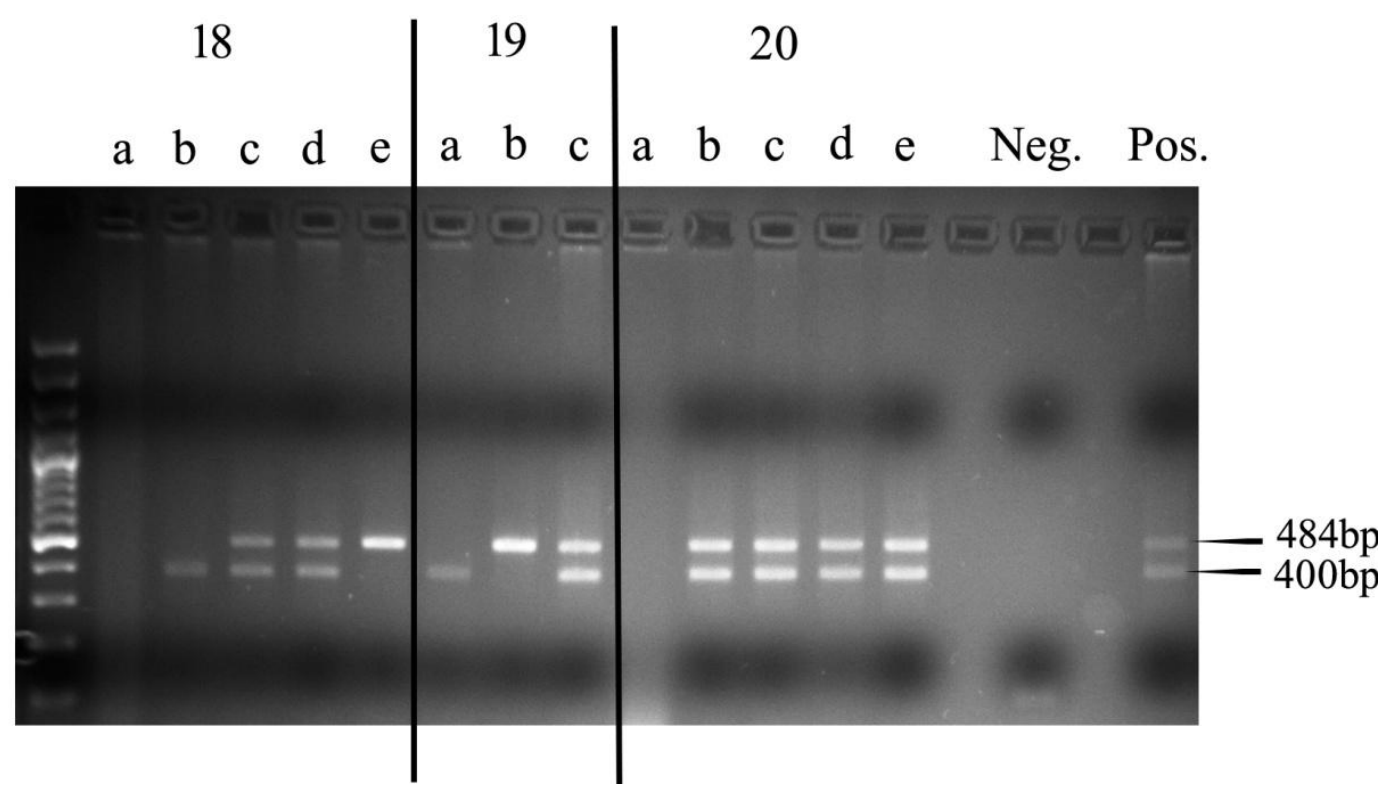

Abb. 5: Gelelektrophorese, gefärbt mit Ethidiumbromid.

Analyse der Embryonen aus den OP-Nummern 18, 19 und 20. Knock-out-DNA: 400 bp (Basenpaare), Wildtyp: 484 bp, Heterozygot: 400 bp und 484 bp; Links außen: Leiter mit jeweils 100 bp Schritten; Neg. = Negativkontrolle; Pos. $=$ Positivkontrolle mit heterozygoter Maus.

Bei Wildtyp-Embryonen erscheint in der Gelelektrophorese nur eine Bande bei 484 bp. Dies ist in Abbildung 5 der Fall bei 18e und 19b. Heterozygote knock-out-Embryonen sind diejenigen, bei denen zwei Banden sichtbar sind, bei 400 bp und bei 484 bp. Heterozygot sind 18c, 18d, 19c, 20b - e. Bei homozygoten knock-out-Embryonen erscheint eine Bande bei 400 bp, das sind die Nummern 18b und 19a.

\subsubsection{Fixierung, Einbettung und Schnittanfertigung}

Nach der Präparation wurden die Präparate für 15 Minuten in 4\%iger ParaformaldehydLösung fixiert, damit das Gewebe nicht zerfällt. Anschließend wurden sie dreimal mit PBS gewaschen und dann über Nacht in 10\%iger Saccharose-Lösung in den Kühlschrank gestellt. Am nächsten Tag wurde die Lösung erneut gewechselt und die Präparate für fünf Stunden in 30\%iger Saccharose-Lösung getränkt. 
Das Ziel der Fixierung war, dass Größe, Form, Moleküleigenschaften, Färbbarkeit, Antigenität und Enzymaktivitäten sich nicht verändern sollten. Für Kryostat-Schnitte wurde eine chemische Fixierung und eine Entwässerung vermieden.

Es folgte die Einbettung in Tissue Tek, dem Kryomedium. Unter dem Mikroskop wurde das Präparat im Gel in die richtige Position gebracht und eventuelle Blasen wurden beiseitegeschoben, sodass das Präparat blasenfrei von Kryomedium umgeben war. Die Einbettung war wichtig, damit im Anschluss dünne Schnitte hergestellt werden konnten. Das Einbetten geschah in einer vorher aus Aluminiumfolie hergestellten eckigen Form, auf der mit einem schwarzen Edding die untere Seite des Präparates markiert wurde, sodass man beim Schneiden später eine Orientierung hatte. Die beschrifteten Präparate wurden nun bei $-20{ }^{\circ} \mathrm{C}$ eingefroren.

Mit Hilfe des Kryotoms wurden im Anschluss Gefrierschnitte hergestellt. Die Kühltemperatur betrug dabei im Kühlraum $-23{ }^{\circ} \mathrm{C}$ und am Objektträger $-25^{\circ} \mathrm{C}$.

Das Objekt wurde aus der Aluminiumfolie ausgepackt und mit einem Tropfen Einbettmedium auf dem Objektträger fixiert. Man wartete bis das Objekt festgefroren war und spannte es nun in das Gerät ein. Dieses arbeitete nach dem Prinzip eines Rotationsmikrotoms. Als erstes musste das Objekt getrimmt werden, bis man das Präparat bereits makroskopisch erkennen konnte. Dann wurden die Seiten mit einer Rasierklinge gerade geschnitten und es konnte mit den Schnittanfertigungen begonnen werden. Die ersten Schnitte wurden auf einen Objektträger aufgenommen und unter dem Mikroskop untersucht. Dort erkannte man, ob das Präparat richtig angeschnitten war.

Das Kryotom wurde auf $18 \mu \mathrm{m}$ pro Schnitt eingestellt und pro Objektträger wurden drei Schnitte aufgenommen. Die Objektträger wurden je nach Bezeichnung des Präparates entsprechend beschriftet und nummeriert. Nach dem Aufnehmen der Schnitte wurde der Objektträger ca. eine Minute auf eine $37{ }^{\circ} \mathrm{C}$ warme Heizplatte gelegt, damit sich die Schnitte strecken konnten. Es wurden Superfrost-Objektträger benutzt, sodass die Schnitte im Anschluss bei $-20{ }^{\circ} \mathrm{C}$ bis zur weiteren Verarbeitung eingefroren werden konnten. 


\subsubsection{Immunfluoreszenz-Färbung}

Zunächst wurden geeignete Schnitte herausgesucht, die gefärbt werden sollten. Aus dem Entwicklungstag 12,5 wurden Schnitte aus dem Halsbereich gewählt, in dem sich die Lymphsäcke befinden. In den darauf folgenden Stadien waren sowohl in Bauchhaut als auch in Rückenhaut Lymphgefäße zu erwarten. Dementsprechend wurden von den ganzen Embryonen vom ED 14,5 im Bereich des Thorax Schnitte gesucht, Lymphsäcke waren nicht mehr in Jugularregion zu erwarten.

Diese Objektträger mit den Schnitten mussten für eine Stunde trocknen. Dann wirkte die BSA-Lösung für eine Stunde bei Raumtemperatur ein. BSA blockiert im Gewebe die unspezifischen Bindungsstellen für die Antikörper. Anschließend wurden die Primärantikörper in der in 2.1.3 aufgeführten Verdünnung auf die Objektträger gegeben, je Objektträger wurden $200 \mu \mathrm{l}$ gerechnet. Diese Schritte passierten in einer feuchten Kammer. Wichtig dabei war die Spezies, von der der Antikörper stammt, und gegen welche Spezies sich der Antikörper richtet. Beide Antikörper richteten sich gegen Mausproteine, kamen aber von unterschiedlichen Tieren. Die Antikörper gegen MausProx1 kamen vom Kaninchen und die Antikörper gegen Maus-Ki67 stammten von einer Ratte. Die unterschiedliche Herkunft war wichtig für die weitere Verarbeitung. Prox1 wird in Lymphendothelzellen exprimiert (Wigle und Oliver 1999), Ki67 in allen proliferierenden Zellen (Scholzen und Gerdes 2000). Die Primärantikörper inkubierten über Nacht im Kühlschrank mit dem Präparat. Am nächsten Tag wurden die Objektträger zweimal in PBS gewaschen, um nicht gebundene primäre Antikörper zu entfernen. Dann wurden die Sekundärantikörper eine Stunde bei Raumtemperatur in der feuchten Kammer mit dem Präparat inkubiert. Man wählte hier die sekundären Antikörper, die an die primären Antikörper binden, also sich gegen die Proteine von Kaninchen und Ratte richten. Diese Antikörper sind an ein Fluorochrom gekoppelt. Prox1 sollte später rot erscheinen, also war der Sekundärantikörper gegen Kaninchenproteine an Alexa 594 gekoppelt. Ki67 sollte grünes Licht senden, weswegen der sekundäre Antikörper gegen Rattenproteine an Alexa 488 gekoppelt war. Dazu wurde außerdem der Zellkernfarbstoff Dapi gegeben.

Der letzte Schritt war das Eindeckeln. Dazu wurden die Objektträger zunächst zweimal mit PBS gewaschen. Danach wurde Fluoromount $G$ mit einem Glasstab auf die Deckgläser aufgebracht und diese langsam über die gefärbten Präparate gelegt, sodass keine Blasen entstehen konnten. Über Nacht wurde alles bei Raumtemperatur 
getrocknet. Nach dem Trocknen wurden die gefärbten Schnitte im Kühlschrank aufbewahrt. Die Auswertung sollte zeitnah erfolgen, da die Fluoreszenzfarbstoffe ansonsten ausbleichen könnten.

\subsubsection{Auswertung}

Die Auswertung erfolgte mit Hilfe des Fluoreszenzmikroskops DM5000B. Die in der Färbung enthaltenen Fluorochrome senden rotes, grünes oder blaues Licht aus, wenn sie mit Licht einer bestimmten Wellenlänge bestrahlt werden. Filter im Mikroskop trennen das Emissionslicht vom Anregungslicht, sodass man ein sauberes Bild erhält.

Es wurden jeweils verschiedene Fotos mit unterschiedlichem Anregungslicht von derselben Stelle gemacht, sodass man drei digitale Aufnahmen erhält, die mit einem Programm überlagert wurden. Die Prox1 positiven Zellkerne senden rotes Licht, die Ki67 positiven Zellkerne grünes Licht. Dapi emittiert blaues Licht.

Von den Schnitten wurden Fotos gemacht, die sowohl als zvi-Datei als auch als jpgDatei gespeichert wurden. Die Fotos wurden mit einer 400-fachen Vergrößerung aufgenommen und ausgewertet. Es wurden unter anderem Übersichtsfotos mit einer 100-fachen Vergrößerung aufgenommen, die nur der Veranschaulichung dienten und nicht zur Auswertung genutzt wurden.

Die einzelnen Fotos wurden mit Hilfe des Programmes Axiovision Rel. 4.6 ausgewertet. In dem Programm konnte man zwischen den einzelnen Kanälen wechseln, sodass man genau überprüfen konnte, welche Zellkerne positiv waren. Das Ziel war herauszufinden, welche Zellkerne doppelt positiv waren, also Prox1 und Ki67exprimierten. Da Dapi alle Zellkerne färbt, konnte man damit zusätzlich überprüfen, ob es sich um einen Zellkern oder ein Artefakt handelte.

Die doppelt positiven Zellkerne wurden markiert. In einem zweiten Schritt wurden alle anderen Prox 1 positiven Zellkerne markiert und es konnte eine Datentabelle erzeugt werden. Daraus ließ sich nun errechnen, wie viel Prozent der Prox1 positiven Zellen auch Ki67 positiv waren. Dies wurde schriftlich festgehalten. 


\section{Ergebnisse}

In vorherigen Arbeiten wurde die Hypothese aufgestellt, dass homozygote Wnt5a koMäuse größere und dafür weniger Lymphgefäße besitzen, die Anzahl der Lymphendothelzellen sei allerdings vermutlich dieselbe im Vergleich zu WildtypMäusen (Buttler et al. 2013). Das würde bedeuten, dass Wnt5a zwar die Morphogenese, also die Form, Netzwerkbildung oder Migration der Lymphgefäße, nicht aber die Proliferation der Lymphendothelzellen beeinflusst. In der Arbeit von Buttler et al. (2013) wurden Embryos des Embryonaltages 18,5 untersucht. Desweiteren wurden die heterozygoten ko-Embryos mit den Wildtyp-Embryos gleichgesetzt und als Kontrollgruppe mit den homozygoten ko-Embryonen verglichen.

In meiner Arbeit untersuche ich nun die Proliferation der Lymphendothelzellen in den verschiedenen Entwicklungsstadien der Embryonen. Untersucht wurden Embryonen der Entwicklungstage ED 12,5, ED 14,5, ED 16,5 und ED 18,5. Außerdem wurde unterschieden zwischen Wildtyp und heterozygoten Genträgern und denen, bei denen das Gen nicht vorhanden ist, die sogenannten homozygoten knock-out (ko) -Mäuse. Die Präparate (siehe 2.2 Methoden) wurden mit einer Immunfluoreszenztechnik zur weiteren Auswertung gefärbt. Wie oben beschrieben, sind die Zellen, die Prox1 im Zellkern exprimieren, rot gefärbt und somit als Lymphendothelzellen identifizierbar. Die zweite Färbung erfolgte mit Ki67, das in allen proliferierenden Zellen ebenfalls im Zellkern (grün) exprimiert wird. In der Doppelfärbung ergibt sich daraus ein gelbes Signal (Abb. 6b). Mit diesen Informationen konnte genau gezählt und ausgerechnet werden, wie viel Prozent der Lymphendothelzellen zum Untersuchungszeitpunkt proliferieren. 

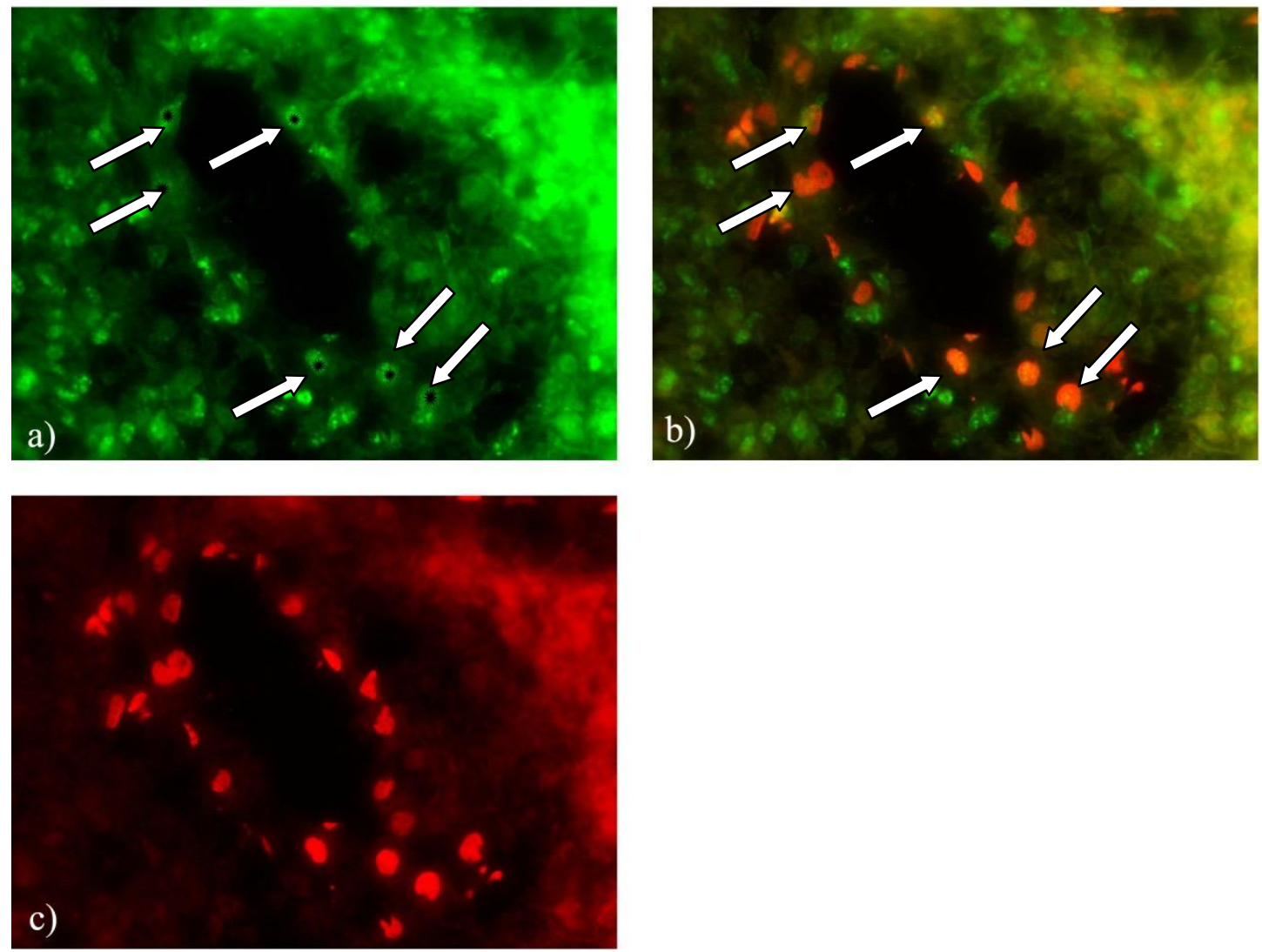

Abb. 6: Auswertung anhand eines Beispiels

a) Ki67 exprimierende Zellkerne mit Markierung b) Grüner und roter Kanal übereinander gelegt; c) Nur Prox1 positive Zellkerne (rot) sind zu erkennen. Die Pfeile verweisen auf doppelt positive Zellkerne

Abbildung 6 zeigt beispielhaft die Auswertung der einzelnen Fotos. Erst wurde nach Lymphendothelzellen gesucht, die rot erscheinen. Dann wurde nur der grüne Kanal betrachtet (siehe Abb. 6a) und indem der rote Kanal immer wieder dazu geschaltet wurde (siehe Abb. 6b), konnten diejenigen Zellen markiert werden, die doppelt positiv sind. Im Anschluss werden die übrigen Zellen gezählt, die nicht doppelt positiv sind, aber trotzdem zum Gefäß gehören (siehe Abb. 6c).

Für jedes Stadium (ED 12,5, ED 14,5, ED 16,5 und ED 18,5) und jeden Genotyp (Wildtyp: wt; heterozygoter knock-out: het; homozygoter knock-out: ko) wurden jeweils zwei verschiedene Embryonen verwendet (siehe Tabelle 3). Da der Genpool der Mäuse des Black6-Stammes zu Forschungszwecken durch Inzucht immer ähnlich gehalten wird, wurden auch zwei Embryonen desselben Muttertieres als unterschiedlich angesehen. Nun wurden von jedem Embryo mindestens zwei Objektträger untersucht 
und ausgewertet. Je nachdem, ob genug verwendbare Fotos entstanden, wurden weitere Schnittpräparate untersucht. Insgesamt sollte die Anzahl der Fotos in jedem Stadium bei allen drei Genotypen ähnlich und damit vergleichbar sein. Durchschnittlich habe ich 46,2 Fotos pro Entwicklungstag und Genotyp angefertigt und auf jedem Foto ca. 10 Lymphendothelzellen ausgewertet, sodass sich eine Gesamtzahl von mehr als 5544 ausgewerteten Lymphendothelzellen ergibt. 
Tabelle 3: Übersicht der untersuchten Embryos

\begin{tabular}{|c|c|c|c|c|c|}
\hline ED & Genotyp & $\begin{array}{c}\text { OP- } \\
\text { Nummer }\end{array}$ & Embryo & $\begin{array}{l}\text { Anzahl der } \\
\text { Fotos }\end{array}$ & $\begin{array}{c}\text { Fotos } \\
\text { gesamt }\end{array}$ \\
\hline \multirow[t]{6}{*}{12,5} & wt & 2 & A & 19 & \\
\hline & & 2 & F & 12 & 31 \\
\hline & het & 2 & I & 4 & \\
\hline & & 2 & M & 19 & 23 \\
\hline & ko & 2 & $\mathrm{E}$ & 19 & \\
\hline & & 2 & $\mathrm{k}$ & 16 & 35 \\
\hline \multirow[t]{6}{*}{14,5} & wt & 40 & 4 & 43 & \\
\hline & & 40 & $7 \mathrm{a}$ & 11 & 54 \\
\hline & het & 40 & $3 b$ & 20 & \\
\hline & & 40 & $5 b$ & 34 & 54 \\
\hline & ko & 40 & $2 a$ & 22 & \\
\hline & & 40 & 1 & 34 & 56 \\
\hline \multirow[t]{7}{*}{16,5} & wt & 27 & $3 a$ & 27 & \\
\hline & & 27 & $3 b$ & 5 & \\
\hline & & 34 & $\mathrm{C} 2$ & 18 & 50 \\
\hline & het & 33 & $\mathrm{C} 3$ & 18 & \\
\hline & & 33 & B7 & 31 & 49 \\
\hline & ko & 34 & A2 & 29 & \\
\hline & & 34 & B2 & 14 & 43 \\
\hline \multirow[t]{6}{*}{18,5} & wt & 13 & A & 36 & \\
\hline & & 9 & $4 b / 3$ & 23 & 59 \\
\hline & het & 13 & $\mathrm{C}$ & 14 & \\
\hline & & 9 & $3 b / 3$ & 31 & 45 \\
\hline & ko & 13 & B & 26 & \\
\hline & & 9 & $1 \mathrm{a} / 3$ & 27 & 53 \\
\hline
\end{tabular}




\subsection{Embryonaltag 12,5}

\subsubsection{Mikroskopische Ergebnisse}
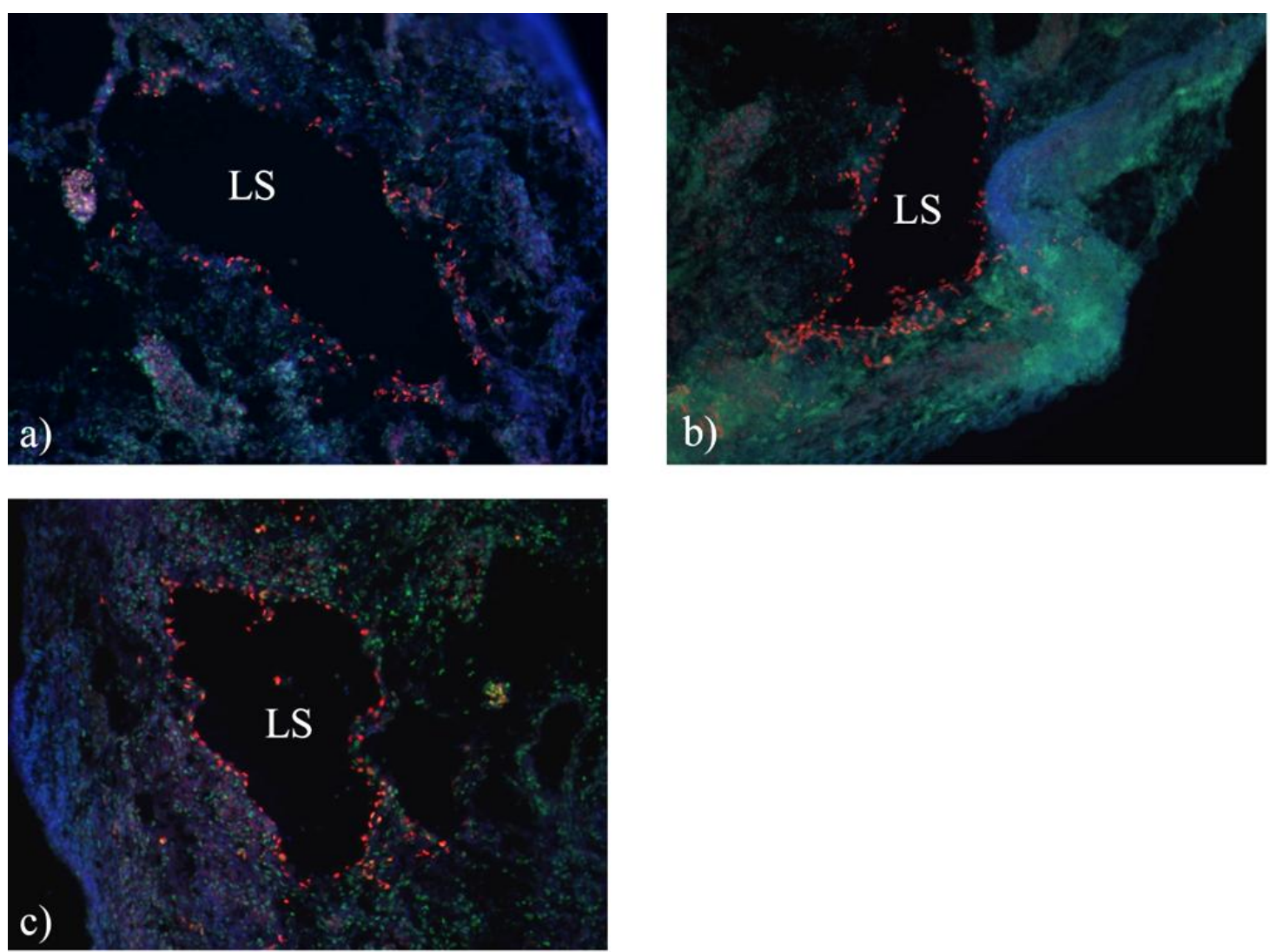

Abb. 7: Übersicht der Lymphsäcke von ED 12,5 Embryonen

Vergrößerung 100-fach; in rot sind die Lymphendothelzellen zu erkennen. a) Lymphsack eines Wildtyp-Embryos; b) Lymphsack eines heterozygoten ko-Embryos; c) Lymphsack eines homozygoten ko-Embryos. LS - Lymphsack.

Abbildung 7 zeigt die mikroskopischen Fotos der verschiedenen Genotypen von Embryonen des Stadiums ED 12,5. In diesem Stadium wurde nach Lymphsäcken in der Jugularregion gesucht, denn die Differenzierung in Lymphgefäße findet erst später statt. Dementsprechend wurden hier ganze Embryonen eingebettet, geschnitten und gefärbt (siehe 2.2.2 Fixierung, Einbettung und Schnittanfertigung). Diese Übersichten wurden in einem nächsten Schritt vergrößert, um jede Zelle einzeln beurteilen zu können (siehe Abb. 8 und 9). Man erkennt die Lymphsäcke an der Umrandung mit Prox1 positiven Zellen, den Lymphendothelzellen. 

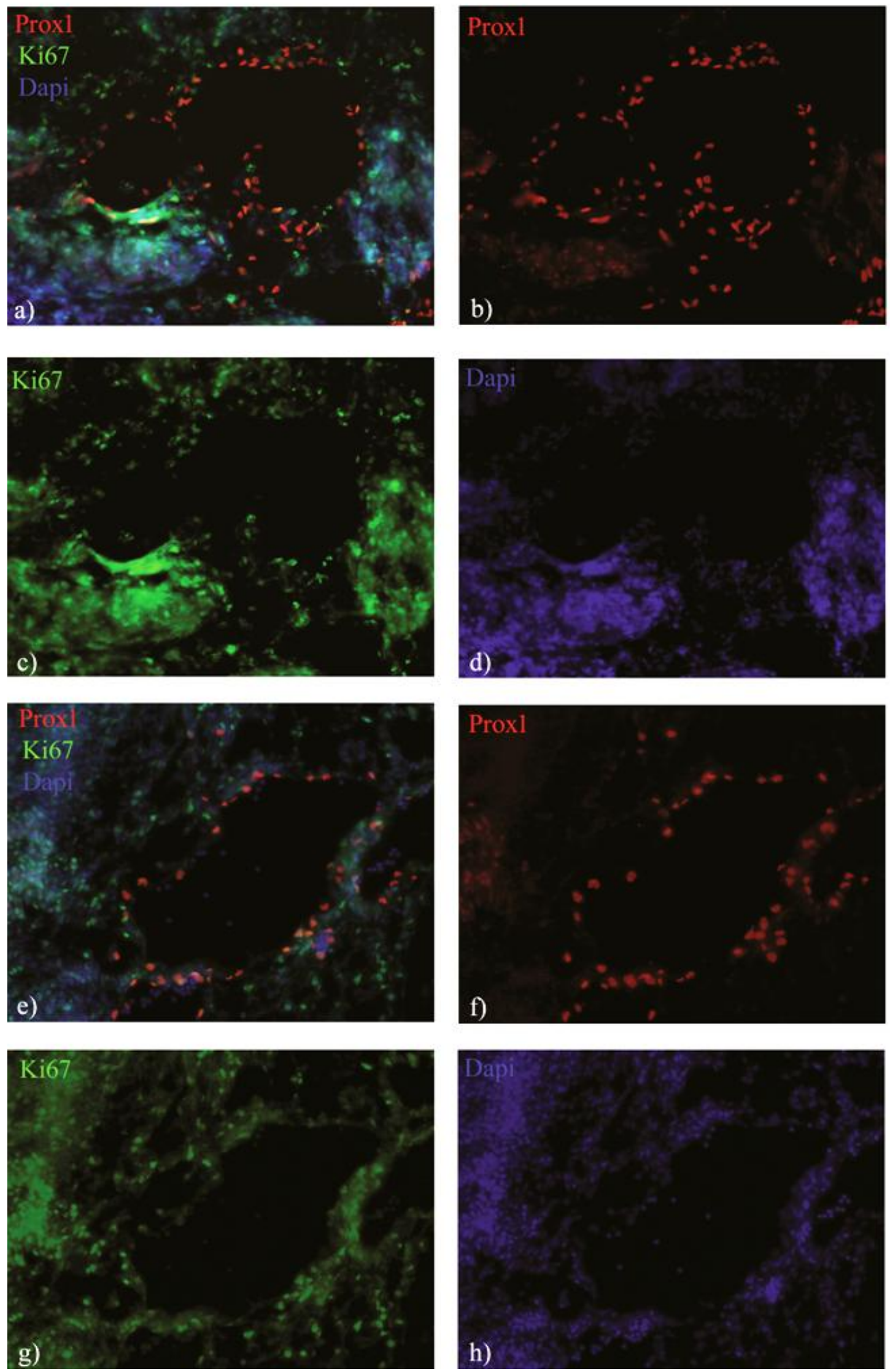

Abb. 8: Mikroskopische Fotos ED 12,5 
Abbildung 8 zeigt die mikroskopischen Fotos von Embryonen des Stadiums ED 12,5 in 200-facher Vergrößerung. a) - d) sind Fotos eines Wildtyp-Embryos, e) - h) Fotos eines heterozygoten ko-Embryos. Die Kanäle wurden für ein Gesamtbild in a) und e) zusammen gesetzt, in b) und f) sind nur die Zellkerne gezeigt, die Prox1 exprimieren. c) und g) zeigen die Zellkerne, die Ki67 exprimieren und d) und h) zeigen die Zellkerne nach Dapi-Färbung.

Abbildung 9 zeigt mikroskopische Fotos eines homozygoten ko-Embryos ED 12,5. Im Gegensatz zu denen in Abbildung 8, sind diese in einer höheren Vergrößerung aufgenommen. Exemplarisch sind einige proliferierende Lymphendothelzellen mit weißen Pfeilen markiert. In allen Abbildungen a) - c) sind jeweils dieselben Zellkerne markiert.
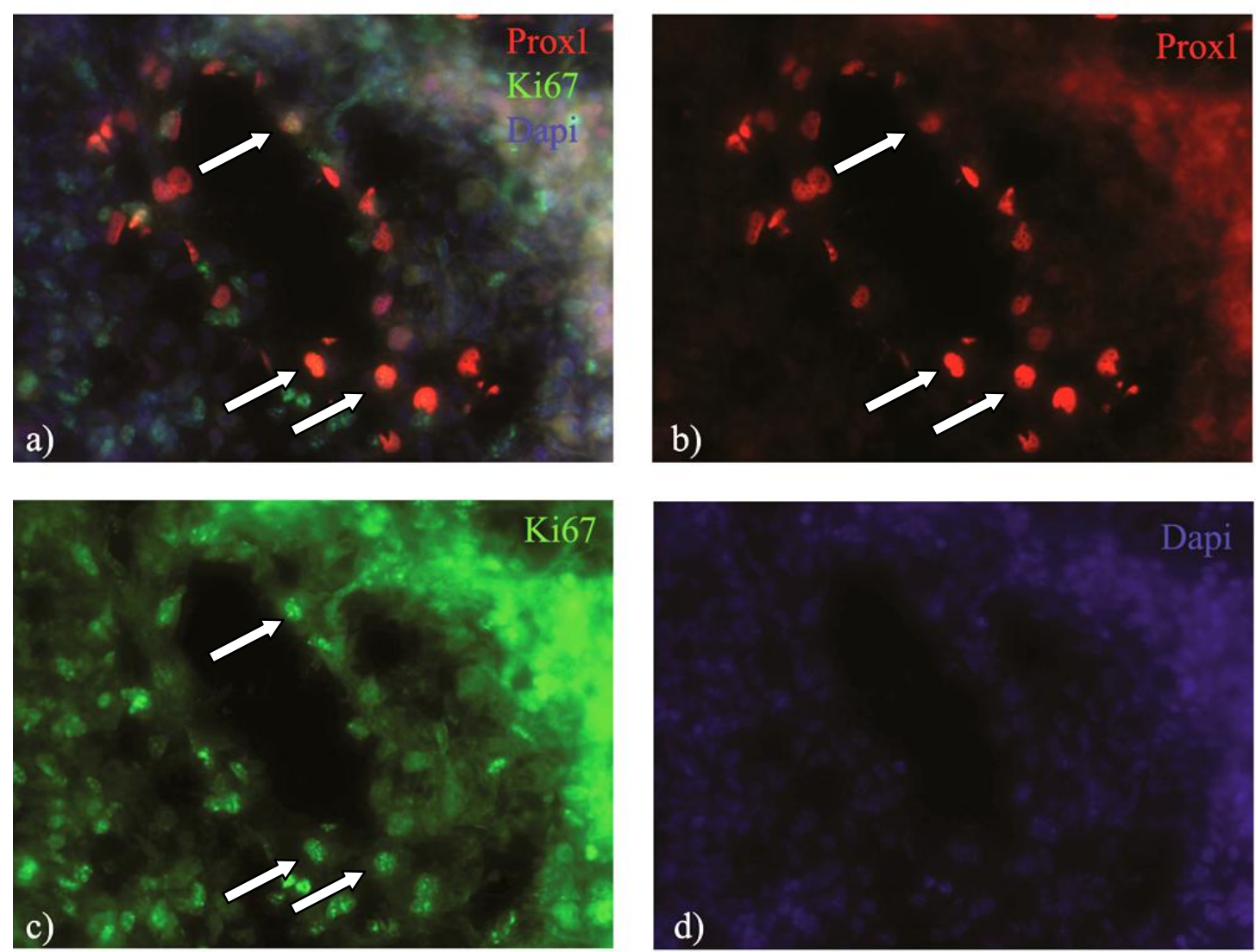

Abb. 9: Mikroskopische Fotos eines homozygoten ko-Embryos ED 12,5

400-fache Vergrößerung; a) Zusammenlegung der drei Kanäle; b) Zellkerne, die Prox1 exprimieren; c) proliferierende Zellkerne, die Ki67 exprimieren; d) Mit Dapi gefärbte Zellkerne. Die Pfeile verweisen auf proliferierende Lymphendothelzellen. 


\subsubsection{Statistische Auswertung}

\section{ED 12,5}

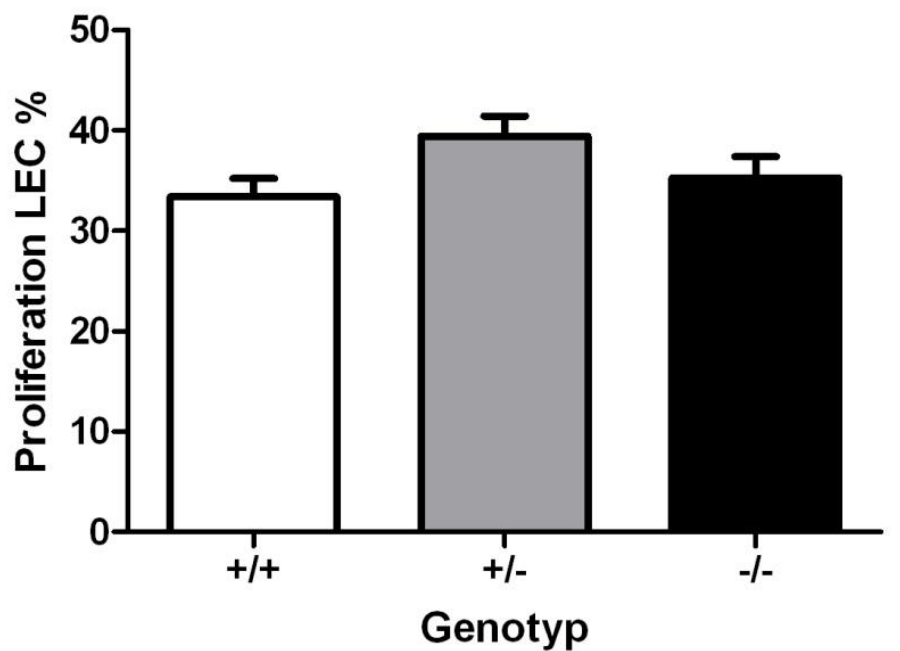

Abb. 10: Graphische Darstellung der Ergebnisse für ED 12,5

Die y-Achse zeigt die Proliferation der Lymphendothelzellen (LEC) in Prozent, die $x$-Achse zeigt die verschiedenen Genotypen (wt: +/+, het: +/-, ko: -/-). Die Standardabweichungen sind dargestellt

Nachdem in den Fotos nach Lymphsäcken gesucht worden war und diese Zellen ausgezählt worden waren, konnte die statistische Auswertung mit diesen Zahlen durchgeführt werden. Abbildung 10 zeigt ein Balkendiagramm mit der statistischen Auswertung der Ergebnisse für den Embryonaltag 12,5. Insgesamt wurden zur Auswertung für jeden Genotyp zwei Embryonen benutzt. Für den Wildtyp wurden 31 Fotos gemacht (siehe Tabelle 3) und die Zellen ausgezählt. Dabei stellte sich heraus, dass im Durchschnitt 33,39\% aller Lymphendothelzellen, die in den Präparaten gefunden wurden, proliferierende Zellen sind. Bei der Auswertung der heterozygoten ko-Embryonen wurden 23 Fotos ausgewertet. Die Anzahl der proliferierenden Zellen beläuft sich hier im Mittel auf 39,42\%. Für die homozygoten ko-Mäuse wurden 35 Fotos gemacht. Das Ergebnis im Mittel sind 35,28\% proliferierende Zellen.

Die Statistik wurde mit dem Programm GraphPadPrism 5 durchgeführt, und es wurden die Tests „One Way Anova“ und der Post-Test „Tukey“ angewendet, der jeden Wert einzeln vergleicht. Ein Wert wurde als signifikant abweichend angegeben, wenn $\mathrm{p}<$ 0,05. Alle Vergleiche der Genotypen untereinander ergaben aber keinen signifikanten Unterschied in der Proliferation der Lymphendothelzellen. Der Wert für $\mathrm{p}$ wird mit 
0,1390 angegeben. Die mittlere Abweichung der Werte zwischen wt und het liegt bei $-6,035$, zwischen wt und ko bei $-1,893$ und zwischen het und ko bei 4,142. Der Unterschied ist nicht signifikant.

\subsection{Embryonaltag 14,5}

\subsubsection{Mikroskopische Ergebnisse}
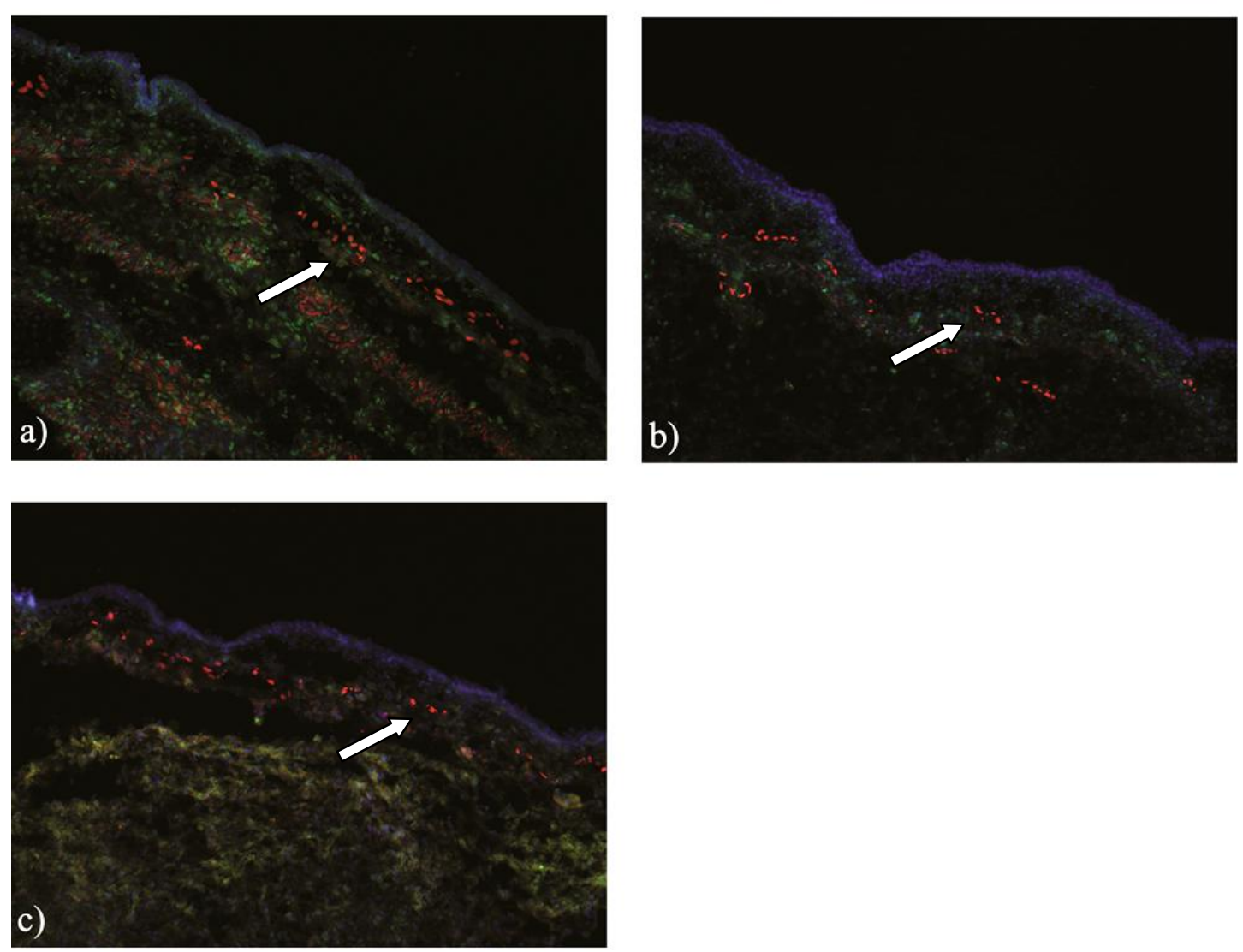

Abb. 11: Übersicht der Hautpräparate der Embryonen ED 14,5

100-fache Vergrößerung; Lymphendothelzellen erscheinen rot. Die äußere Schicht der Epidermis erscheint blau, da diese Zellkerne deutlich von Dapi gefärbt wurden, also keine Lymphendothelzellen und auch keine proliferierenden Zellen darstellen. a) Initiale Lymphgefäße eines Wildtyp-Embryos; b) Initiale Lymphgefäße eines Heterozygoten koEmbryos; c) Initiale Lymphgefäße eines homozygoten ko-Embryos. Die Pfeile verweisen auf Lymphgefäße. 
Im Stadium ED 14,5 kann man in den Übersichten in Abbildung 11 erkennen, dass hier in der Haut nach kleinen initialen Lymphgefäßen gesucht wurde. In diesem Stadium wurden sowohl ganze Embryonen als auch Hautpräparate eingebettet und untersucht (siehe 2.2.2 Fixierung, Einbettung und Schnittanfertigung). In den ganzen Embryonen wurde dann am äußeren Rand des Präparates in der Haut nach Lymphgefäßen gesucht.

Mikroskopische Fotos der Präparate für den Embryonaltag 14,5 sind in Abbildung 12 bei 400-facher Vergrößerung zu sehen. Die Fotos a) - d) zeigen Hautschnitte eines Wildtyp-Embryos, die Fotos e) - h) die Hautschnitte eines heterozygoten ko-Embryos. Die Kanäle wurden für ein Gesamtbild in a) und e) zusammen gesetzt, in b) und f) sind nur die Zellkerne gezeigt, die Prox1 exprimieren. c) und g) zeigen die Zellkerne, die Ki67 exprimieren und d) und h) zeigen die Zellkerne mittels Dapi-Färbung. Die Pfeile zeigen auf doppelt positive Zellkerne, also proliferierende Lymphendothelzellen. Diese erscheinen gelblich in den zusammen gelegten Bildern a) und e). Die Pfeile verweisen in a) - c) und in e) - g) jeweils auf die gleichen Zellen. 

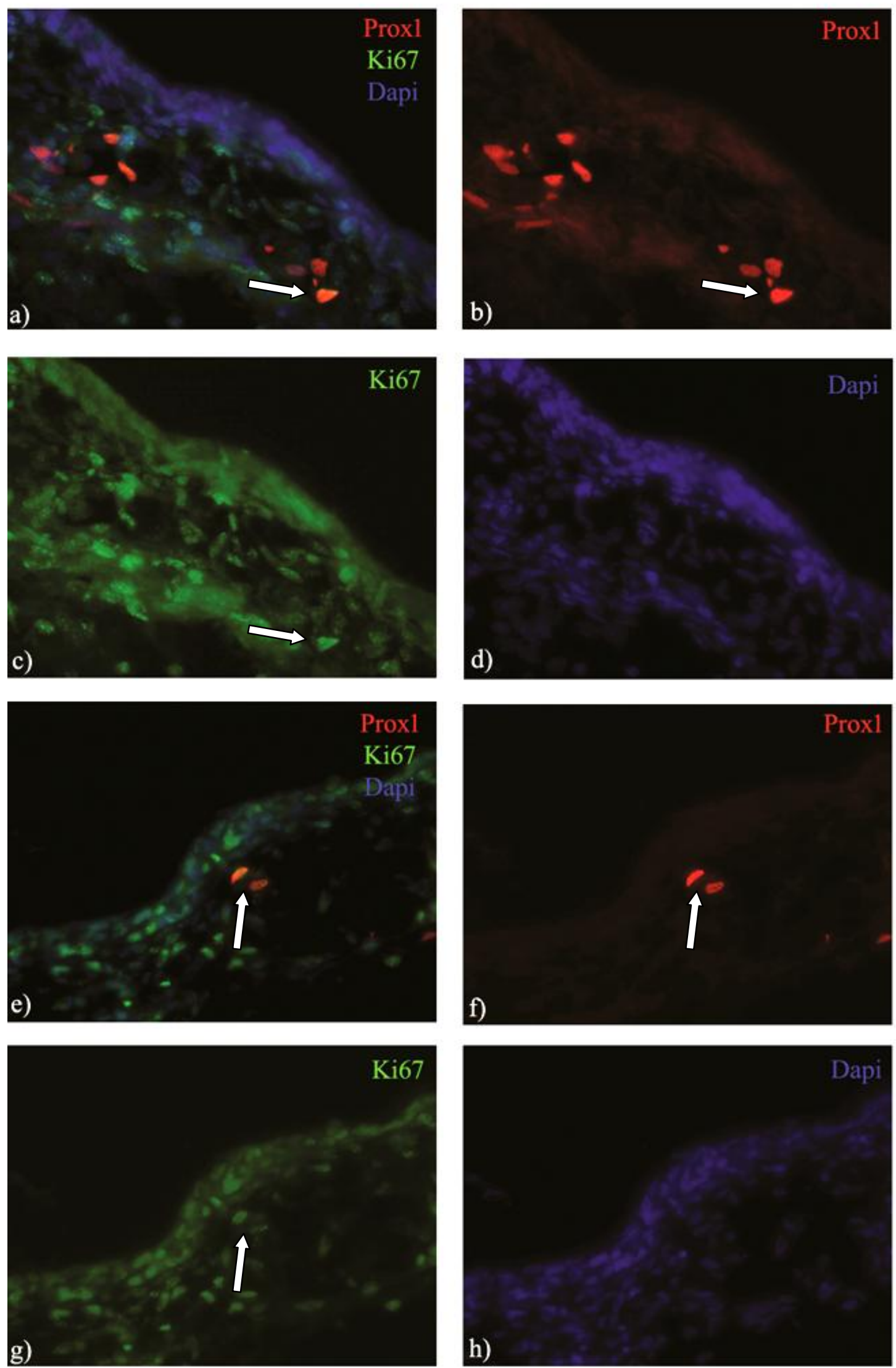

Abb. 12: Mikroskopische Fotos ED 14,5

400-fache Vergrößerung; a)-d) Wildtyp; e)-h) Heterozygoter ko-Embryo 

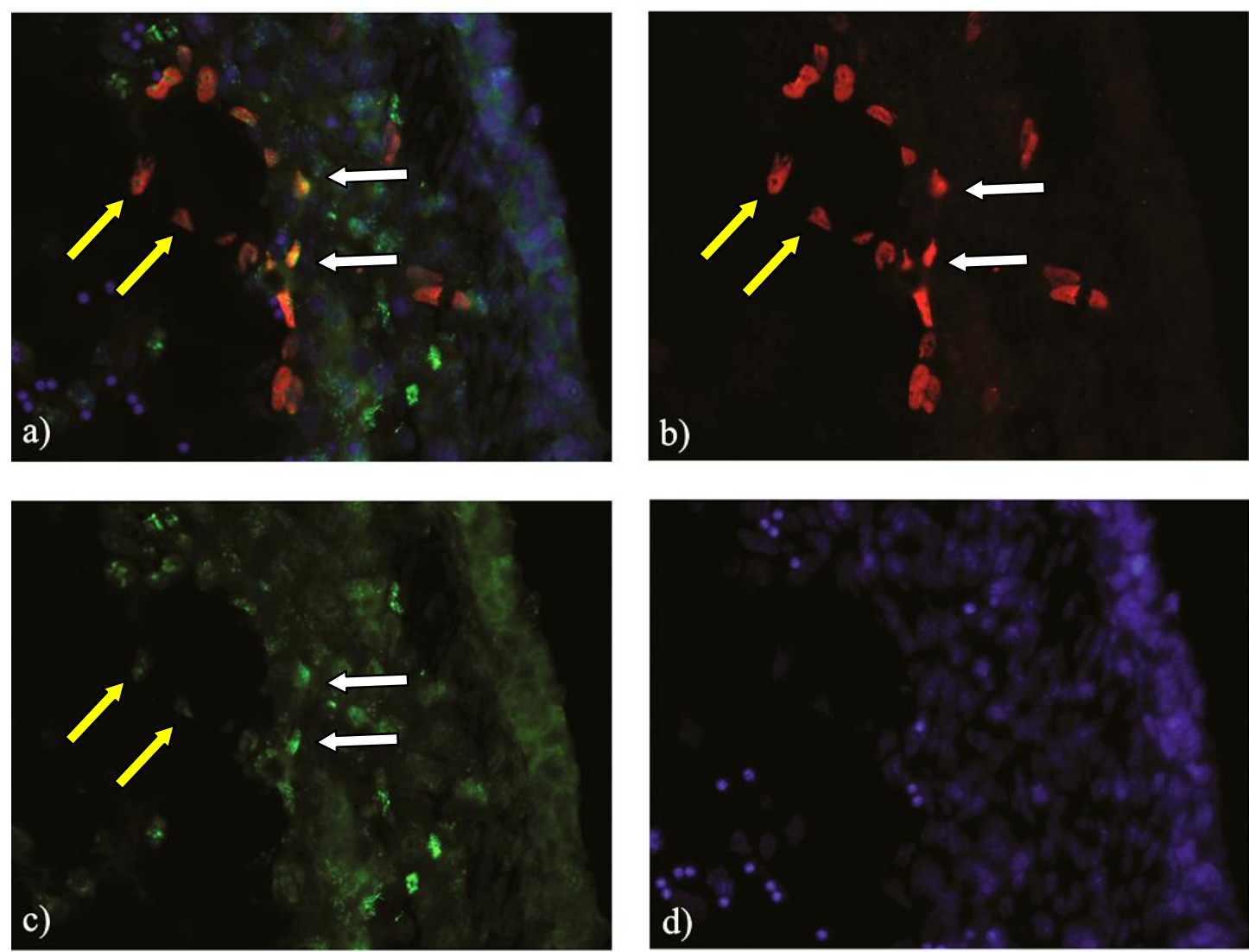

Abb. 13: Mikroskopische Fotos eines homozygoten ko-Embryos ED 14,5

a) Alle Kanäle in einem Bild; b) Prox1 exprimierende Zellen; c) Ki67 exprimierende Zellen; d) Dapi-gefärbte Zellen. Alle Pfeile zeigen auf proliferierende Zellen.

Abbildung 13 zeigt Fotos eines homozygoten ko-Embryos ED 14,5. Die weißen Pfeile verweisen auf offensichtlich proliferierende Zellen. Diese erscheinen im Gesamtbild a) gelb und man kann auf den ersten Blick erkennen, dass sie doppelt positiv sind. Die Zellen, auf die die gelben Pfeile zeigen, sind auch doppelt positiv. Das erkennt man jedoch erst, wenn man sich die verschiedenen Bilder einzeln betrachtet. Die Auswertung muss letztendlich bei höherer Vergrößerung durchgeführt werden. 


\subsubsection{Statistische Auswertung}

\section{ED 14,5}

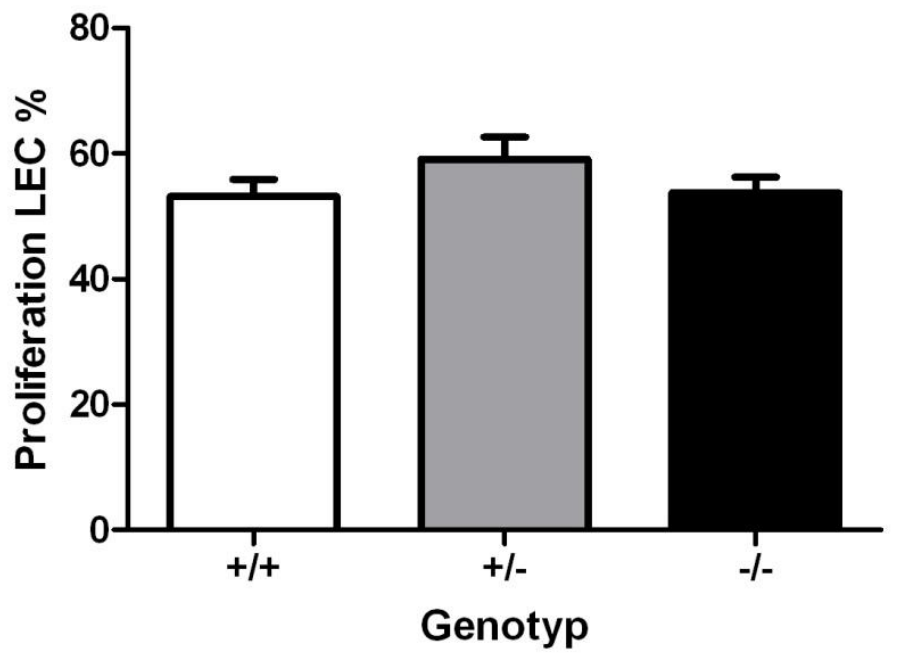

Abb. 14: Graphische Darstellung der Ergebnisse für ED 14,5

Die $y$-Achse zeigt die Proliferation der LEC in Prozent, die $x$-Achse zeigt die verschiedenen Genotypen (wt: +/+, het: +/-, ko: -/-). Ein signifikanter Unterschied zwischen den Gruppen existiert nicht. Die Standardabweichungen sind dargestellt.

Abbildung 14 zeigt ein Balkendiagramm mit der statistischen Auswertung für den Embryonaltag 14,5. Auf der x-Achse sind die unterschiedlichen Genotypen zu erkennen, auf der y-Achse ist die Proliferation der Lymphendothelzellen in Prozent aufgetragen. Für jeden Genotypen wurden zwei verschiedene Embryonen untersucht (siehe Tabelle 3). Für den Wildtyp wurden 54 Fotos ausgewertet. 53,14\% der Lymphendothelzellen proliferierten. Bei der Auswertung für den heterozygoten ko-Typ wurden ebenfalls 54 Fotos ausgewertet. Der prozentuale Anteil der proliferierenden Lymphendothelzellen lag hier im Mittel bei 59,09\%. 56 Fotos wurden von den homozygoten ko-Präparaten ausgewertet. Dabei lag der Prozentsatz der proliferierenden Zellen im Mittel bei 53,74\%.

Die Auswertung mittels „One Way Anova“ und dem Post-Test „Tukey“ ergab erneut beim Vergleich aller Genotypen untereinander keine Signifikanz im Unterschied der Anzahl der proliferierenden Lymphendothelzellen. Der Wert p wird mit 0,2960 angegeben. Der Vergleich zwischen wt und het ergab eine mittlere Abweichung von $-5,944$, zwischen wt und ko lag dieser Wert bei $-0,5985$ und zwischen het und ko bei 5,346. Es gibt keinen signifikanten Unterschied. 


\subsection{Embryonaltag 16,5}

\subsubsection{Mikroskopische Ergebnisse}
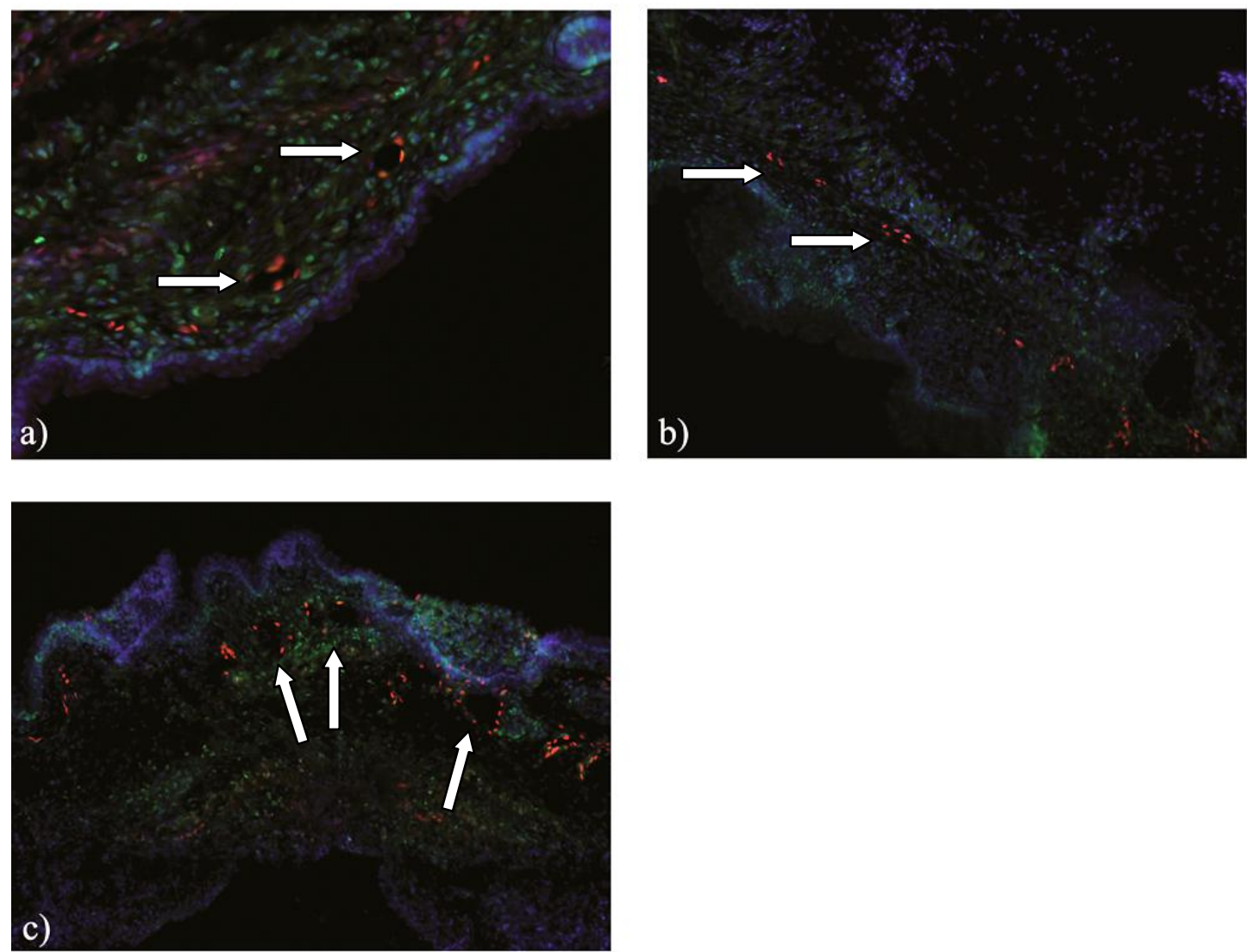

Abb. 15: Übersicht der Hautpräparate der Embryonen ED 16,5

200-fache Vergrößerung bei a) und 100-fache Vergrößerung bei b) und c); Lymphendothelzellen erscheinen rot; Zellkerne blau und proliferierende Zellen grün; a) Initiale Lymphgefäße eines Wildtyp-Embryos; b) Initiale Lymphgefäße eines heterozygoten ko-Embryos; c) Initiale Lymphgefäße eines homozygoten ko-Embryos. Die Pfeile zeigen auf Lymphgefäße.

In Abbildung 15 kann man gut die einzelnen Lymphgefäße erkennen, die mit Pfeilen markiert sind. Abbildung 14a) wurde mit einer anderen Vergrößerung aufgenommen. Dennoch kann man einen Unterschied zu dem Präparat des homozygoten ko-Embryos in c) erkennen. Die Lymphgefäße scheinen in c) viel größer zu sein. 

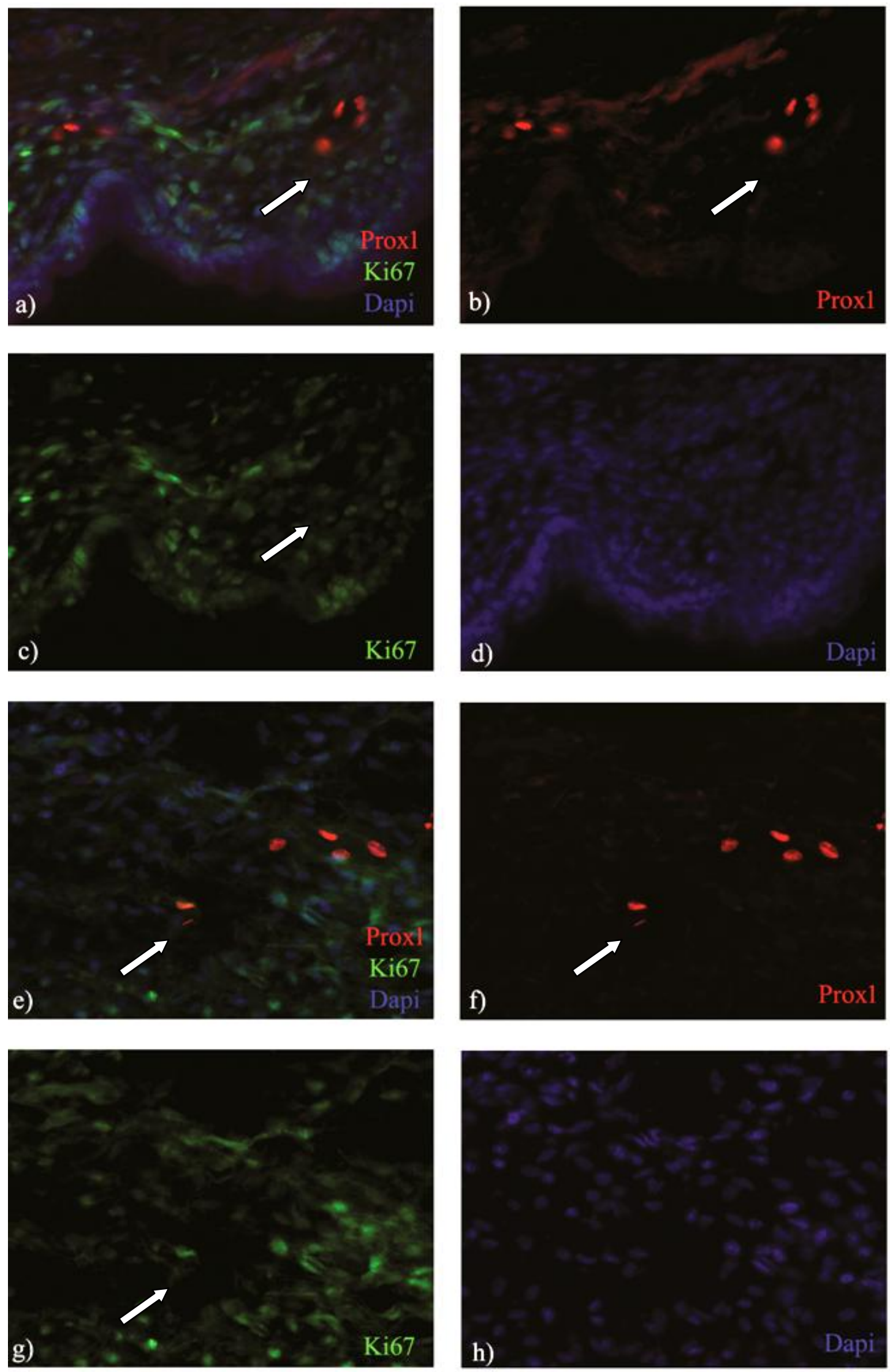

Abb. 16: Mikroskopische Fotos ED 16,5

400-facheVergrößerung; a)-d) Wildtyp; e)-h) heterozygoter ko-Embryo 
In Abbildung 16 sind die mikroskopischen Fotos eines Wildtyp und eines heterozygoten ko-Embryos zu sehen. In a) ist schwer zu erkennen, welcher Zellkern doppelt positiv ist und es müssen alle Kanäle einzeln genau betrachtet werden. Die Pfeile zeigen die doppelt positiven Zellkerne. In e) hingegen ist es schon zu erahnen, dass der mit dem Pfeil markierte Zellkern Prox1 und Ki67 exprimiert, da er gelblicher erscheint.
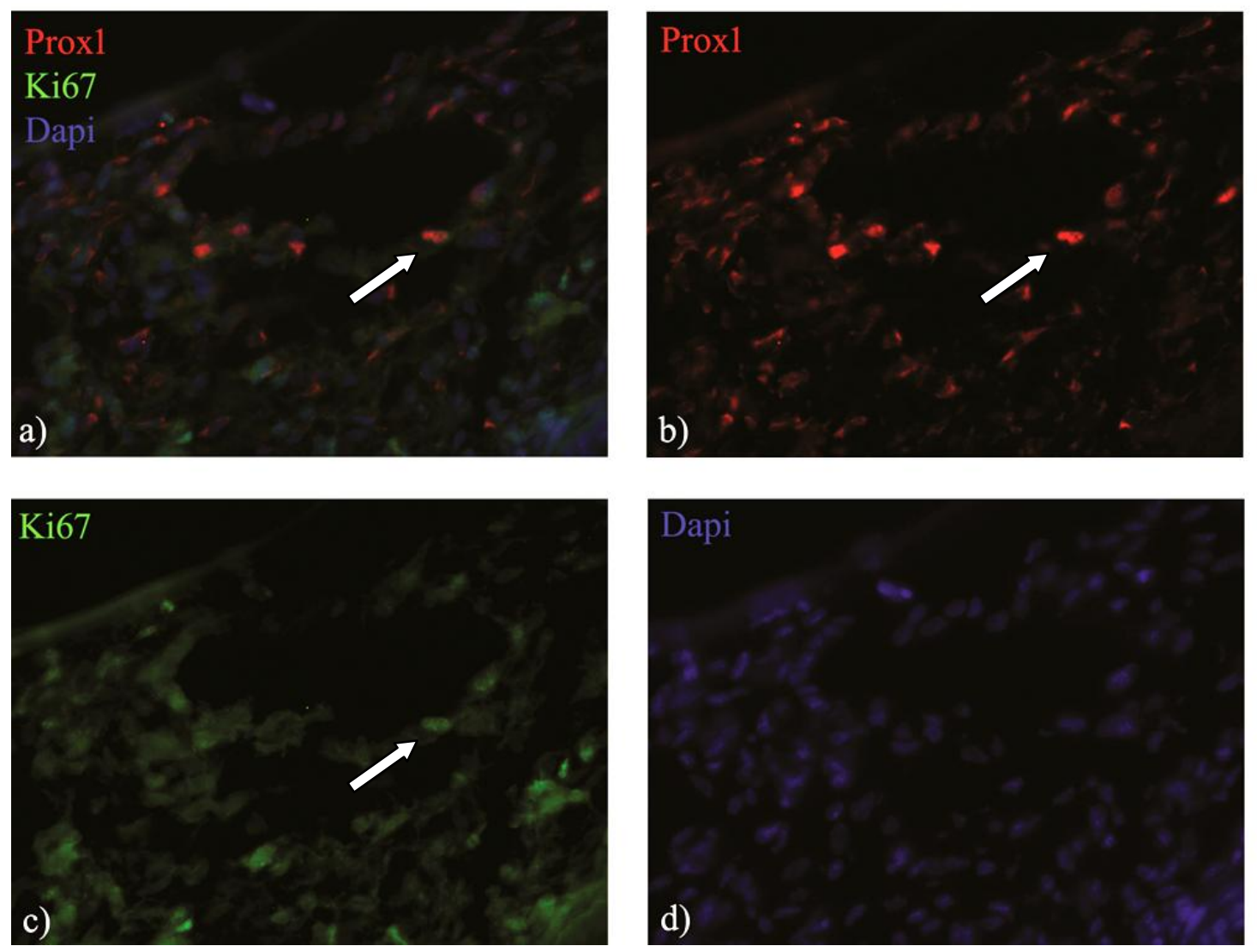

Abb. 17: Mikroskopische Fotos eines homozygoten ko-Embryos ED 16,5

400-fache Vergrößerung; a) alle Kanäle zusammen gelegt; b) Prox1 exprimierende Zellkerne; c) Ki67 exprimierende Zellkerne; d) mit Dapi gefärbte Zellkerne. Der Pfeil zeigt auf einen doppelt positiven Zellkern. Auch hier ist gut zu erkennen, dass bei diesem knockout-Embryo vergrößerte Lymphgefäße vorliegen. Die Proliferation lässt sich erst mit der statistischen Auswertung näher beschreiben. 


\subsubsection{Statistische Auswertung}

\section{ED 16,5}

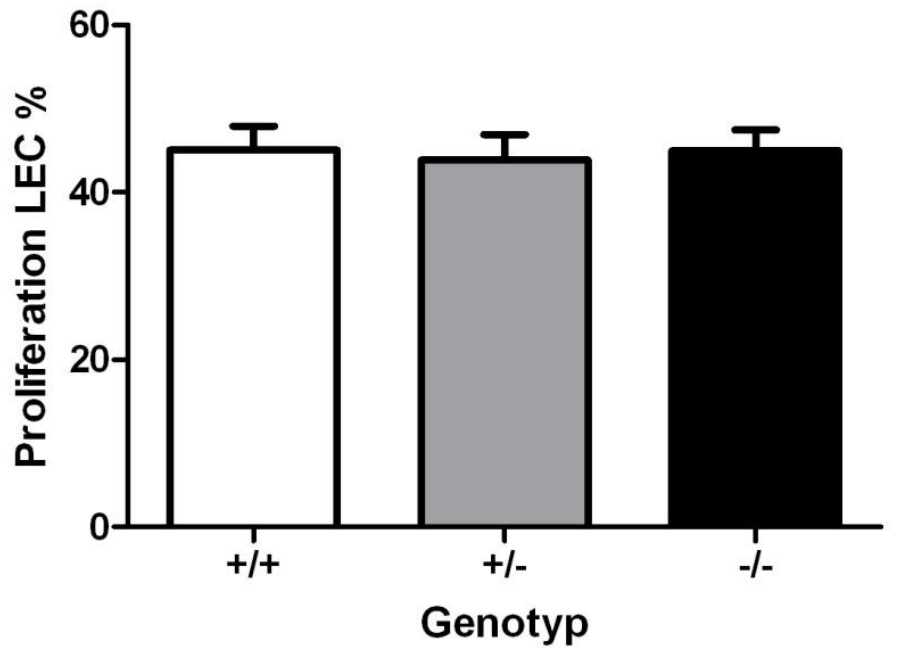

Abb. 18: Graphische Darstellung der Ergebnisse für ED 16,5

Die $y$-Achse zeigt die Proliferation der LEC in Prozent, die $x$-Achse zeigt die verschiedenen Genotypen (wt: +/+, het: +/-, ko: -/-). Die Standardabweichungen sind dargestellt.

Abbildung 18 zeigt ein Balkendiagramm mit den Ergebnissen für den Embryonaltag 16,5. Es wurden wieder zwei verschiedene Embryonen pro Genotyp ausgewertet (siehe Tabelle 3). 45,06\% der Lymphendothelzellen konnten im Mittel als proliferierend betrachtet werden. Für den heterozygoten ko-Typ wurden 49 Fotos ausgewertet und der Anteil der proliferierenden Zellen lag hier im Mittel bei 43,89\%. Von den knock-outEmbryonen wurden 43 Fotos gemacht und ausgewertet. Es stellte sich heraus, dass im Mittel 44,97\% der Lymphendothelzellen proliferieren.

Auch hier ergaben die statistischen Tests „One Way Anova“ und der Post-Test „Tukey“ folgendes: Die Prozentsätze der proliferierenden Lymphendothelzellen der verschiedenen Genotypen waren im Vergleich zueinander nicht signifikant unterschiedlich, was man auch schon am Diagramm erkennen kann. Der Wert p wird mit 0,9468 angegeben. Der Vergleich zwischen wt und het zeigt eine mittlere Abweichung von 1,172, zwischen wt und ko liegt der Wert bei 0,08558 und zwischen het und ko bei -1,087. Die Unterschiede sind nicht signifikant. 


\subsection{Embryonaltag 18,5}

\subsubsection{Mikroskopische Ergebnisse}
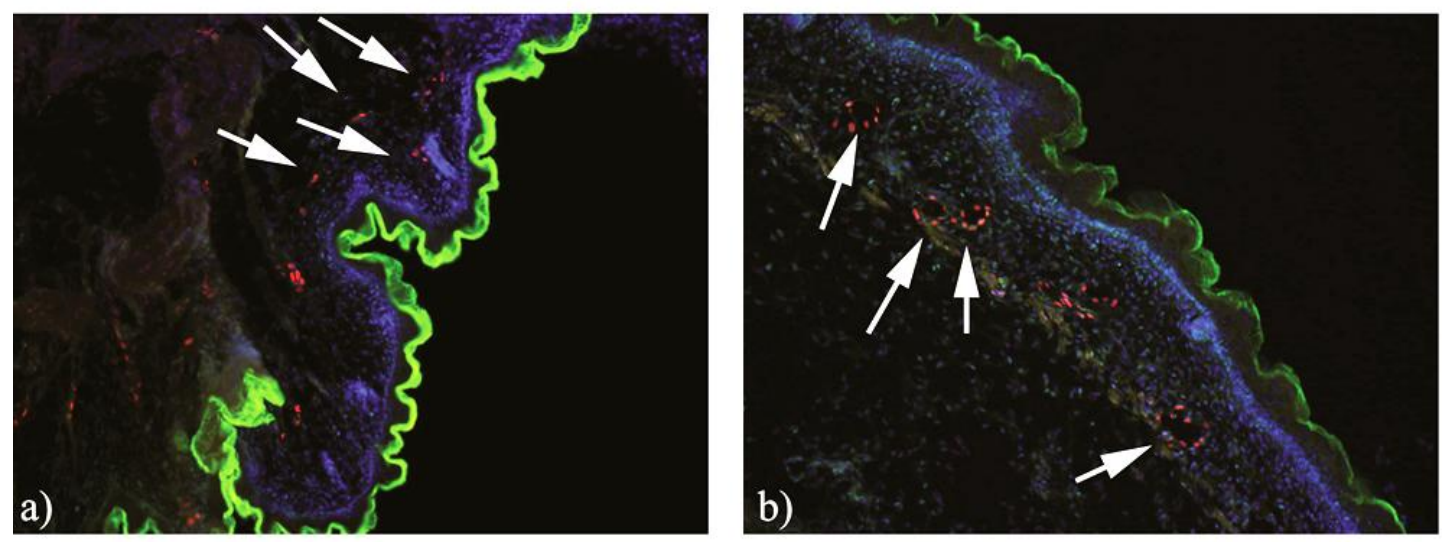

Abb. 19: Übersicht der Hautpräparate ED 18,5

100-fache Vergrößerung; Lymphendothelzellen erscheinen rot, proliferierende Zellen grün und alle Zellkerne blau; a) Präparat eines Wildtyp-Embryos; b) Präparat eines homozygoten ko-Embryos. Die Pfeile verweisen auf Lymphgefäße.

In Abbildung 19 sieht man mikroskopische Bilder für das Entwicklungsstadium ED 18,5. Hier sind nur Bilder von einem Wildtyp-Embryo und einem homozygotem koEmbryo gezeigt, weil es keine Übersichtsaufnahme eines heterozygoten ko-Embryos gibt. Hier sieht man genauso wie auch schon im vorherigen Stadium ED16,5, dass es Unterschiede in der Morphologie der Lymphgefäße gibt. Die Lumina der einzelnen Gefäße scheinen im Vergleich zum Wildtyp-Embryo vergrößert.

In Abbildung 20 sieht man mikroskopische Fotos eines Wildtyp-Embryos a) - d) und eines heterozygoten ko-Embryos e) - h). Die Pfeile zeigen auf doppelt positive Zellen. In den Einzelbildern b) und c) kann man erkennen, dass der markierte Zellkern sowohl Prox1 als auch Ki67 exprimiert. In den Abbildungen 19 e) - h) des heterozygoten koEmbryos ist zu erkennen, dass dort keine der Lymphendothelzellen Ki67 exprimiert, also proliferiert. 

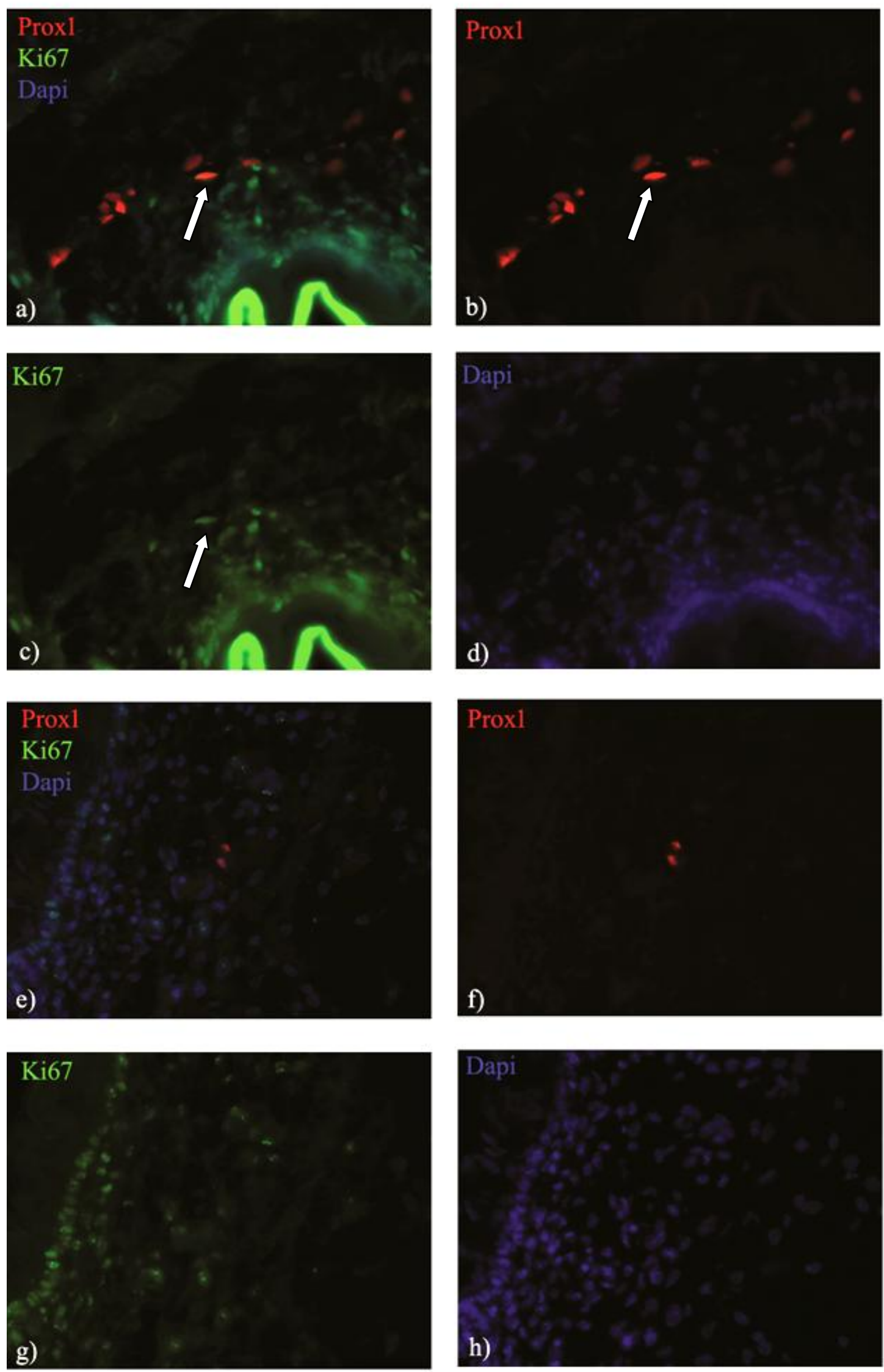

Abb. 20: Mikroskopische Fotos ED 18,5, Wildtyp und heterozygoter ko 

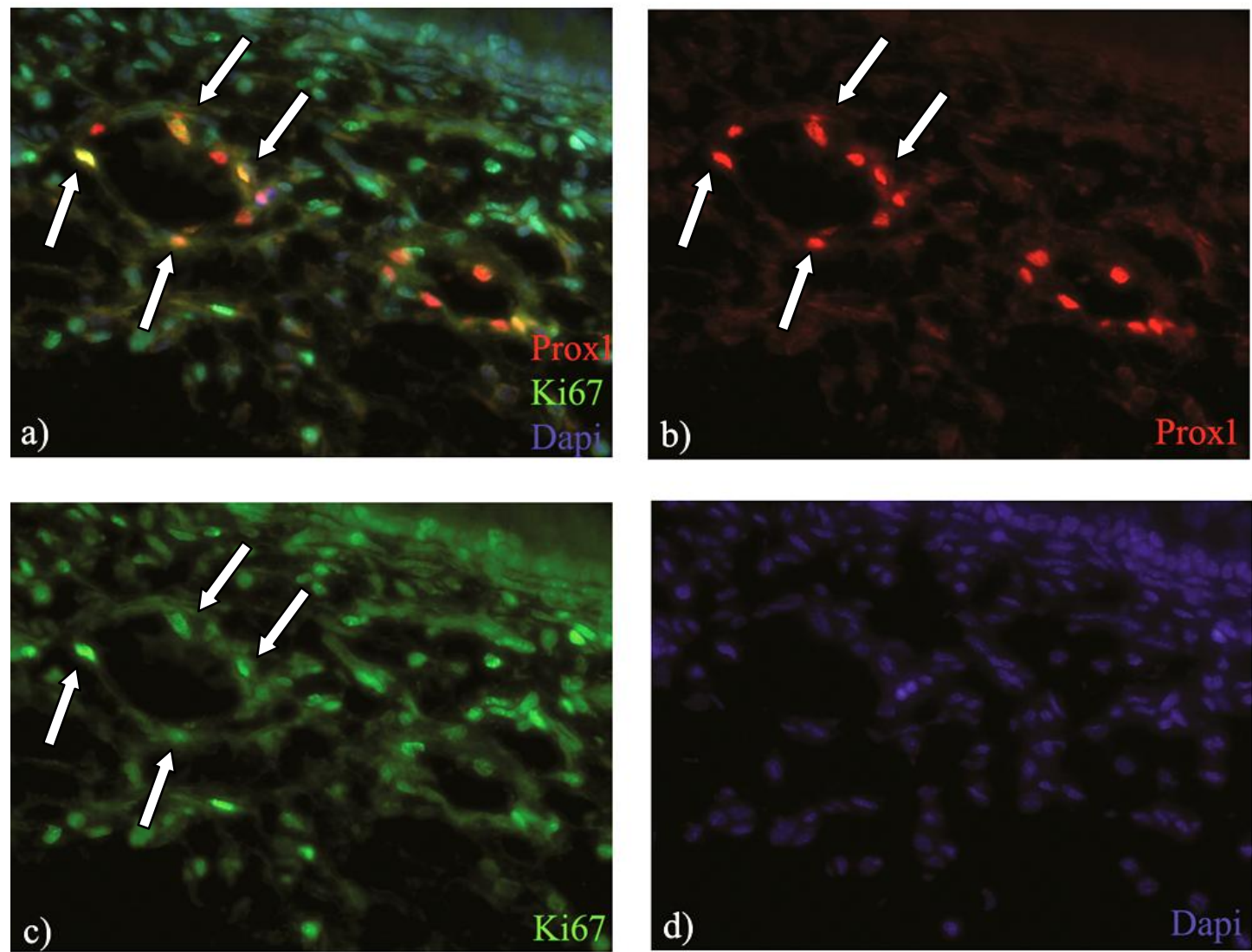

Abb. 21: Mikroskopische Fotos eines homozygoten ko-Embryos ED 18,5

400-fache Vergrößerung; a) Zusammengesetztes Bild mit allen Kanälen; b) Prox1 exprimierende Zellkerne; c) Ki67 exprimierende Zellkerne; d) Dapi-gefärbte Zellkerne. Die Pfeile zeigen auf doppelt positive Zellkerne. Diese erscheinen deshalb gelb.

In Abbildung 21 sieht man die mikroskopischen Bilder eines homozygoten ko-Embryos ED 18,5. Im Vergleich zu Abbildung 20 kann man deutlich das vergrößerte Lumen der Lymphgefäße erkennen. Gut zu erkennen sind auch die doppelt positiven Zellkerne (Abb. 21); die weißen Pfeile weisen darauf hin. Statistisch gesehen gibt es aber keinen signifikanten Unterschied in der Proliferation der Lymphendothelzellen (siehe 3.4.2 Statistische Auswertung). 


\subsubsection{Statistische Auswertung}

\section{ED 18,5}

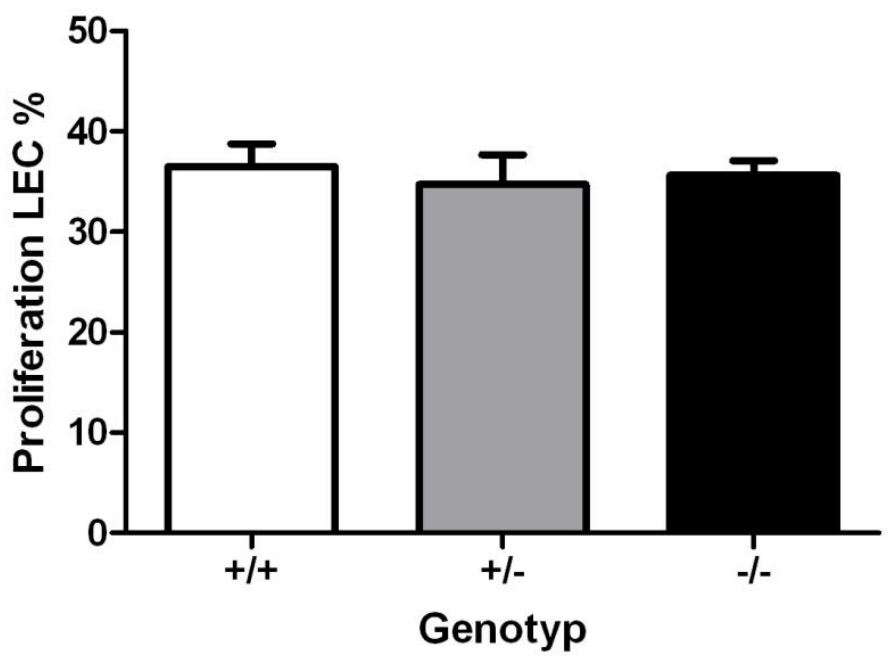

Abb. 22: Graphische Darstellung der Ergebnisse für ED 18,5

Die $y$-Achse zeigt die Proliferation der LEC in Prozent, die $x$-Achse zeigt die verschiedenen Genotypen (wt: +/+, het: +/-, ko: -/-). Die Standardabweichungen sind dargestellt.

Abbildung 22 zeigt ein Balkendiagramm zu den Ergebnissen für den Embryonaltag 18,5. Wieder wurde für jeden Genotyp mit zwei verschiedenen Embryonen gearbeitet (siehe Tabelle 3). Bei der Auswertung des Wildtyps wurden 59 Fotos untersucht. Dabei ließ sich im Mittel eine Proliferation von 36,51\% der Lymphendothelzellen feststellen. Für den heterozygoten ko-Embryo wurden 45 Fotos ausgewertet. Hier lag der Prozentsatz der Proliferation im Mittel bei 34,74\%. Zur Auswertung der homozygoten ko-Embryos wurden 53 Fotos bewertet. Die Auswertung ergab, dass 35,65\% der Lymphendothelzellen im Mittel proliferieren.

Die statistische Auswertung ergab mit dem Test „One Way Anova“ und dem Post-Test „Tukey“, dass auch hier keine signifikanten Unterschiede in der Proliferation festzustellen sind. Der Vergleich der einzelnen Genotypen miteinander ergab Folgendes: Zwischen wt und het besteht eine mittlere Abweichung von 1,763, zwischen wt und ko von 0,8523 und zwischen het und ko liegt die mittlere Abweichung bei 0,9106. Wieder gibt es keine signifikanten Unterschiede. 


\section{Diskussion}

Das Lymphgefäßsystem ist in vielerlei Hinsicht wichtig. Es reguliert den Wasserhaushalt, ist für die Aufrechterhaltung der Flüssigkeitshomöostase zuständig und steuert die Immunabwehr und Entzündungsreaktionen. Außerdem ist es auch in wichtige pathologische Prozesse involviert wie Tumormetastasierung und die Entstehung von Lymphödemen und Lymphangiomen. Daher wird es immer wichtiger zu verstehen, wie sich das Lymphgefäßsystem entwickelt und welche Gene und Regulatoren daran beteiligt sind. Es sind bereits einige Moleküle bekannt, die in der Lymphangiogenese eine Rolle spielen. Das sind zum Beispiel der Wachstumsfaktor VEGF-C und die Transkriptionsfaktoren PROX1 und SOX18 (Witte et al. 2006; Francois et al. 2008).

Ziel meiner Arbeit ist die Untersuchung des sezernierten Glykoproteins Wnt5a aus der Wnt-Genfamilie, das ebenfalls eine Rolle bei der Entwicklung des Lymphgefäßsystems zu spielen scheint. Bei homozygoten ko-Mäusen bilden die initialen Lymphgefäße in der Dermis kein regelmäßiges Netzwerk. Sie sind vielmehr zystenartig erweitert und transportieren keine Lymphe, sodass die Mäuse ödematös erscheinen (Buttler et al. 2013). In der vorliegenden Arbeit habe ich untersucht, ob sich das Fehlen des Wnt5aGens nicht nur auf die Morphologie des Lymphgefäßsystems, sondern auch auf die Proliferation der Lymphendothelzellen bei transgenen Wnt5a knock-out-Mäusen auswirkt bzw. sich die Malformation der Lymphgefäße sogar auf eine gestörte Proliferation der Lymphendothelzellen zurückführen lässt.

\subsection{Wnt in der Angiogenese}

Die autokrine Sekretion von Wnt5a scheint in der Angiogenese nicht sehr wichtig zu sein, denn es ist in deutlich höherer Konzentration in Lymphendothelzellen zu finden als in Blutendothelzellen. Dennoch wurde ein Zusammenhang zwischen Wnt5 und der Angiogenese entdeckt. Die Angiogenese beinhaltet auch die Entstehung von polarisierten Zellen (sogenannte tip cells) über den PCP Signalweg. Die Mechanismen dahinter sind aber noch nicht vollständig verstanden. Die Hemmung des PCPSignalweges stört das endotheliale Zellwachstum, die Polarität und die Migration. Eine 
Zebrafisch-Wnt5-Mutante, die einen beeinträchtigten PCP-Signalweg hat, weist vaskuläre Entwicklungsfehler auf (Cirone et al. 2008).

Wnt7a/7b spielen in der embryonalen Angiogenese des Gehirns eine Rolle (Noda et al. 2016; Posokhova et al. 2015). Bei Fehlen von Wnt7a/b entwickelte sich das Gehirn nicht normal.

\subsection{Wnt in der Lymphangiogenese}

Im Gegensatz zu anderen Mitgliedern der Wnt-Genfamilie findet man Wnt5a in deutlich erhöhter Konzentration in Lymphgefäßen. Es ist zudem in den Anlagen von Extremitäten, Wirbelsäule, Genitalien, Herz, Gesicht und Außenohr lokalisiert. Mäuse, bei denen dieses Gen nicht vorhanden ist, sterben kurz nach der Geburt aufgrund multipler Defekte (Yamaguchi et al. 1999). Sie besitzen verkürzte Extremitäten sowie einen verkümmerten Schwanz. Des Weiteren ist der Unterkiefer stark unterentwickelt und eine Schnauze ist nicht zu erkennen (Buttler et al. 2013). Außerdem sind Lunge und Genitalien fehlentwickelt, der Embryo ist kleinwüchsig und besitzt einen verkürzten Darm sowie Ventrikelseptumdefekte (Oishi et al. 2003). Diese multiplen Defekte des homozygoten knock-out-Embryos zeigen, dass Wnt5a einen erheblichen Einfluss auf die Embryonalentwicklung besitzt. Es steuert Proliferation, Migration, Differenzierung und Apoptose in der Embryonalentwicklung (Logan und Nusse 2004).

Zur Bedeutung von Wnt5a bei der Lymphangiogenese wurden aber nur wenige Untersuchungen durchgeführt. Buttler et. al. (2013) zeigten, dass Wnt5a einen Einfluss auf die Lymphangiogenese der epifaszialen Lymphgefäße hat. Oberflächliche Lymphkollektoren sind in Wnt5a-ko-Mäusen nicht regelgerecht ausgebildet und die initialen Lymphgefäße der Dermis bilden kein regelmäßiges Netzwerk. Die Lymphgefäße zeigen eine veränderte Morphologie im Gegensatz zu Mäusen, die Wnt5a exprimieren. Zur Proliferation von Lymphendothelzellen im Zusammenhang mit Wnt5a gibt es bei der Entwicklung von Mausembryonen noch keine systematischen Untersuchungen. Dieser Frage bin ich in meiner Arbeit nachgegangen.

\subsection{Andere Mitglieder der Wnt-Genfamilie}

Der Wnt-Signalweg und somit die Mitglieder der Wnt-Genfamilie spielen eine große Rolle bei Zelldifferenzierungen, Strukturbildung, Morphogenese, Proliferation und der 
Entstehung von Krankheiten wie Tumoren. Im Folgenden sind einige Wnt-Moleküle und deren Eigenschaften kurz beschrieben.

Wnt6 Expression findet sich besonders in den Nieren. Die Expression korreliert stark mit der Schwere bestimmter Krankheiten, wie z. B. diabetische Nephropathien oder Nierenfibrose, bei denen ein Verlust von Wnt6 festgestellt wurde (Beaton et al. 2016).

Wnt11 spielt eine Rolle in den späteren Stadien der Nierenentwicklung besonders bei der Entwicklung des tubulären Systems (Nagy et al. 2016). Außerdem ist es an der Kardiogenese beteiligt (Hwang et al. 2009).

Wnt $7 \mathrm{a} / \mathrm{b}$ ist wichtig bei der embryonalen Angiogenese des Gehirns und der Bildung der Blut-Hirn-Schranke. Es triggert zusammen mit anderen Molekülen den kanonischen Wnt-Signalweg. Nach Deaktivierung von Wnt7a/b oder des ß-Catenin-Signalweges bilden sich das Gehirn bzw. die Blut-Hirn-Schranke nicht regelgerecht aus (Noda et al. 2016; Posokhova et al. 2015).

\subsection{Proliferation versus Morphogenese}

Bei meinen Untersuchungen bin ich der Frage nachgegangen, ob Wnt5a die Proliferation der Lymphendothelzellen in der Embryonalentwicklung steuert. Es wurde zuvor beschrieben, dass sich bei homozygoten Wnt5a knock-out-Mäusen eine veränderte Morphologie der Lymphgefäße zeigt. Die Lumina der initialen Lymphgefäße der Dermis sind vergrößert, wenn Wnt5a nicht vorhanden ist. Außerdem gibt es weniger Lymphgefäße als in Wildtyp-Mäusen (Buttler et al. 2013). Dies habe ich in meinen Untersuchungen prinzipiell bestätigen können. Daraus wurde geschlossen, dass Wnt5a die Morphogenese beeinflusst, nicht aber die Proliferation. Denn bei der Entstehung weniger aber größerer Gefäße kann man vermuten, dass sich die Anzahl der Lymphendothelzellen innerhalb der verschiedenen Genotypen nicht unterscheidet.

In meinen Untersuchungen ist nun genau diese Hypothese bestätigt worden. Ich habe untersucht, wie viele Lymphendothelzellen in den einzelnen Stadien der Embryonalentwicklung zwischen Tag 12,5 und 18,5 proliferieren und habe dabei die einzelnen Genotypen miteinander verglichen. Den Aspekt der Morphogenese habe ich nicht untersucht, da dieses Thema in einer anderen Arbeit bearbeitet werden soll. Die Ergebnisse meiner Proliferationsuntersuchung sind sehr eindeutig ausgefallen. In keiner der Gruppen bzw. Entwicklungsstadien gab es zwischen den verschiedenen Genotypen 
einen signifikanten Unterschied in der Anzahl der proliferierenden Lymphendothelzellen. Innerhalb der jeweiligen Entwicklungsstadien, ED 12,5, ED 14,5, ED 16,5 und ED 18,5, sind also bei Wildtyp-Mäusen, heterozygoten ko-Mäusen und homozygoten ko-Mäusen keine Unterschiede bezüglich des prozentualen Anteils der proliferierenden Lymphendothelzellen zu beobachten.

Dabei ist die Proliferationsrate in allen Entwicklungsstadien sehr hoch. An Tag 12,5 beträgt sie in den jugulären Lymphsäcken durchschnittlich 36\%. An Tag 14,5 war der Wert mit durchschnittlich 55\% am höchsten. In den Hautlymphgefäßen konnte ich dann an Tag 16,5 einen Wert von $45 \%$ beobachten, der an Tag 18,5 auf 35\% abfiel, was aber immer noch ein vergleichsweise hoher Wert ist. Insgesamt scheint die aktivste Phase der Lymphangiogenese bei Maus um den Embryonaltag 14,5 herum zu liegen.

\subsection{Bewertung der Ergebnisse}

Zusammenfassend kann man sagen, dass das Gen Wnt5a keinen Einfluss auf die Proliferation von Lymphendothelzellen in der Embryonalentwicklung von Mausembryonen besitzt. Dagegen scheint Wnt5a die Morphologie der Lymphgefäße zu beeinflussen, da in meinen Ergebnissen ab ED 16,5 die initialen Lymphgefäße der Dermis vergrößert zu sein scheinen. Die proliferativ aktivste Phase der Lymphangiogenese liegt bei Mausembryonen um den Embryonaltag 14,5 herum.

Die Ergebnisse helfen ein Stück weit, die Lymphangiogenese zu verstehen bzw. welche Moleküle in der Entwicklung des Lymphgefäßsystems eine Rolle spielen. Offensichtlich spielt das sezernierte Glykoprotein Wnt5a eine erhebliche Rolle bei der Embryonalentwicklung, da homozygote knock-out-Embryonen kurz nach der Geburt aufgrund verschiedener Defekte sterben. Die Mäuse sind zudem in späten Embryonalstadien deutlich ödematös, was offensichtlich auf Defekte des Lymphgefäßsystems zurückzuführen ist. Meine Ergebnisse können bestätigen, dass die Proliferation der Lymphendothelzellen nicht von Wnt5a gesteuert wird. Die Fehlentwicklung der Lymphgefäße bei homozygoten knock-out-Mäusen hat ihren Ursprung also nicht in der Proliferation, sondern vielmehr eher in der Migration der Lymphendothelzellen bei der Bildung verzweigter Netzwerke. 


\section{$5 \quad$ Zusammenfassung}

Wnt5a ist ein sezerniertes Glykoprotein der Wnt-Genfamilie. Im Gegensatz zu den anderen Mitgliedern findet sich Wnt5a in deutlich höherer Konzentration in Lymphendothelzellen als in Blutendothelzellen. Es spielt außerdem eine wichtige Rolle in der Embryonalentwicklung. Homozygote knock-out-Mäuse sterben kurz nach der Geburt aufgrund multipler Defekte.

Die Auswirkungen von Wnt5a auf die Entwicklung des Lymphgefäßsystems soll nun näher betrachtet werden. Dazu untersuchte ich immunhistologisch Mausembryonen der verschiedenen Genotypen (Wildtyp, heterozygoter knock-out und homozygoter knockout) in verschiedenen embryonalen Entwicklungsstufen (Embryonaltag [ED] 12,5; ED 14,5; ED 16,5 und ED 18,5). Dabei sollte die Proliferation der Lymphendothelzellen genauer untersucht werden. In vorherigen Arbeiten stellte man die Hypothese auf, dass Wnt5a die Morphologie der initialen Lymphgefäße steuert, nicht aber die Proliferation der Lymphendothelzellen beeinflusst.

Mittels Immunfluoreszenz-Doppelfärbungen mit den Antikörpern Prox1 (markiert den Zellkern der Lymphendothelzellen) und Ki67 (Proliferationsmarker) färbte ich auf histologischen Gefrier-Schnitten die proliferierenden Lymphendothelzellen und konnte sie unter dem Mikroskop zählen und prozentual auswerten.

Dabei verglich ich die Ergebnisse der verschiedenen Genotypen innerhalb der unterschiedlichen Entwicklungsstadien miteinander. Ich konnte die zuvor aufgestellte Hypothese bestätigen. Das sezernierte Regulatorprotein Wnt5a besitzt keinen Einfluss auf die Proliferation der Lymphendothelzellen. In keiner Entwicklungsphase war ein statistisch signifikanter Unterschied in der Anzahl der proliferierenden Lymphendothelzellen festzustellen. Dabei liegt die proliferativ aktivste Phase der Lymphangiogenese bei Mausembryonen mit durchschnittlich 55\% proliferierender Lymphendothelzellen um den Embryonaltag 14,5 herum. Da die Lymphgefäße der homozygoten Wnt5a ko-Mäuse ab ED 16,5 deutlich fehlgebildet aussahen, kann man den Rückschluss ziehen, dass Wnt5a offensichtlich die Morphologie der Lymphgefäße während der Embryonalentwicklung steuert. Wnt5a könnte dabei die Migration der Lymphendothelzellen steuern und so für die Bildung eines regelmäßigen Netzwerkes verantwortlich sein. 
Es muss noch weiter geforscht werden, um den genauen Hintergrund der Lymphangiogenese mit allen molekularen Signalwegen, die beteiligt sind, genau zu verstehen. Damit könnten auch Krankheiten, die das Lymphsystem betreffen (z. B. Malformationen des Lymphgefäßsystems), besser verstanden werden. 


\section{$6 \quad$ Literaturverzeichnis}

Adair TH, Montani JP: Angiogenesis. Morgan \& Claypool Life Sciences, San Rafael (CA) 2010

Alitalo K, Tammela T, Petrova TV (2005): Lymphangiogenesis in development and human disease. Nature $\underline{438}, 946-953$

Bacino C: ROR2-Related Robinow Syndrome; In: GeneReviews(R), edited by Pagon RA, Adam MP, Ardinger HH, Wallace SE, Amemiya A, Bean LJH, Bird TD, Fong C, Mefford HC, Smith RJH Seattle (WA) 1993

Baluk P, Fuxe J, Hashizume H, Romano T, Lashnits E, Butz S, Vestweber D, Corada M, Molendini C, Dejana E (2007): Functionally specialized junctions between endothelial cells of lymphatic vessels. J Exp Med 204, 2349-2362

Beaton H, Andrews D, Parsons M, Murphy M, Gaffney A, Kavanagh D, McKay GJ, Maxwell AP, Taylor CT, Cummins EP (2016): Wnt6 regulates epithelial cell differentiation and is dysregulated in renal fibrosis. Am J Physiol Renal Physiol $\underline{311}$, F $35-45$

Buttler K, Becker J, Pukrop T, Wilting J (2013): Maldevelopment of dermal lymphatics in Wnt5a-knockout-mice. Dev Biol 381, 365-376

Casley-Smith JR (1980): The fine structure and functioning of tissue channels and lymphatics. Lymphology $\underline{13}, 177-183$

Cirone P, Lin S, Griesbach HL, Zhang Y, Slusarski DC, Crews CM (2008): A role for planar cell polarity signaling in angiogenesis. Angiogenesis $\underline{11}, 347-360$

Connell F, Brice G, Mortimer P (2008): Phenotypic characterization of primary lymphedema. Ann NY Acad Sci 1131, 140-146

Dejana E (2010): The role of wnt signaling in physiological and pathological angiogenesis. Circ Res 107, 943-952

Francois M, Caprini A, Hosking B, Orsenigo F, Wilhelm D, Browne C, Paavonen K, Karnezis T, Shayan R, Downes M (2008): Sox18 induces development of the lymphatic vasculature in mice. Nature $\underline{456}, 643-647$

Fukuda T, Chen L, Endo T, Tang L, Lu D, Castro JE, Widhopf GF, Rassenti LZ, Cantwell MJ, Prussak CE (2008): Antisera induced by infusions of autologous AdCD154-leukemia B cells identify ROR1 as an oncofetal antigen and receptor for Wnt5a. Proc Natl Acad Sci USA 105, 3047-3052

Gale NW, Prevo R, Espinosa J, Ferguson DJ, Dominguez MG, Yancopoulos GD, Thurston G, Jackson DG (2007): Normal lymphatic development and function in mice deficient for the lymphatic hyaluronan receptor LYVE-1. Mol Cell Biol 27, 595-604 
Goodwin AM, Kitajewski J, D'Amore PA (2007): Wnt1 and Wnt5a affect endothelial proliferation and capillary length; Wnt2 does not. Growth Factors 25, 25-32

Hwang Y, Chung BG, Ortmann D, Hattori N, Moeller H, Khademhosseini A (2009): Microwell-mediated control of embryoid body size regulates embryonic stem cell fate via differential expression of WNT5a and WNT11. Proc Natl Acad Sci U S A $\underline{106}, 16978-16983$

Keeble TR, Halford MM, Seaman C, Kee N, Macheda M, Anderson RB, Stacker SA, Cooper HM (2006): The Wnt receptor Ryk is required for Wnt5a-mediated axon guidance on the contralateral side of the corpus callosum. J Neurosci $\underline{26}, 5840-5848$

Kukk E, Lymboussaki A, Taira S, Kaipainen A, Jeltsch M, Joukov V, Alitalo K (1996): VEGF-C receptor binding and pattern of expression with VEGFR-3 suggests a role in lymphatic vascular development. Development $122,3829-3837$

Leak LV (1971): Studies on the permeability of lymphatic capillaries. J Cell Biol $\underline{50}$, $300-323$

Logan CY, Nusse R (2004): The WNT signaling pathway in development and disease. Annu. Rev. Cell Dev Biol 20, 781-810

Lohrberg M, Wilting J (2016): The lymphatic vascular system of the mouse head. Cell Tissue Res $\underline{366}$, 667-677

MacDonald BT, Tamai K, He X (2009): Wnt/ $\beta$-Catenin Signaling: Components, Mechanisms, and Diseases. Dev Cell 17, 9-26

Masckauchan TN, Agalliu D, Vorontchikhina M, Ahn A, Parmalee NL, Li CM, Khoo A, Tycko B, Brown AM, Kitajewski J (2006): Wnt5a signaling induces proliferation and survival of endothelial cells in vitro and expression of MMP-1 and Tie-2. Mol Biol Cell 17, 5163-5172

Mikels AJ, Nusse R (2006): Purified Wnt5a protein activates or inhibits beta-cateninTCF signaling depending on receptor context. PLoS Biol $\underline{4}$, e115

Nagy II, Xu Q, Naillat F, Ali N, Miinalainen I, Samoylenko A, Vainio SJ (2016): Impairment of Wnt11 function leads to kidney tubular abnormalities and secondary glomerular cystogenesis. BMC Dev Biol $\underline{16}, 30$

Neufeld G, Cohen T, Gengrinovitch S, Poltorak Z (1999): Vascular endothelial growth factor (VEGF) and its receptors. FASEB J $\underline{13}, 9-22$

Niehrs C (2012): The complex world of WNT receptor signalling. Nat Rev Mol Cell Biol 13, 767-779

Noda M, Vallon M, Kuo CJ (2016): The Wnt7's Tale: A story of an orphan who finds her tie to a famous family. Cancer Sci $\underline{107}, 576-582$

Oishi I, Suzuki H, Onishi N, Takada R, Kani S, Ohkawara B, Koshida I, Suzuki K, Yamada G, Schwabe GC (2003): The receptor tyrosine kinase Ror2 is involved in non-canonical Wnt5a/JNK signalling pathway. Genes Cells $\underline{8}, 645-654$ 
Oliver G, Harvey N (2002): A Stepwise Model of the Development of Lymphatic Vasculature. Ann NY Acad Sci 979, 159-165

Person AD, Beiraghi S, Sieben CM, Hermanson S, Neumann AN, Robu ME, Schleiffarth JR, Billington CJ, van Bokhoven H, Hoogeboom JM (2010): WNT5A mutations in patients with autosomal dominant Robinow syndrome. Dev Dyn 239, $327-337$

Pollmann C, Hagerling R, Kiefer F (2014): Visualization of lymphatic vessel development, growth, and function. Adv Anat Embryol Cell Biol 214, 167-186

Posokhova E, Shukla A, Seaman S, Volate S, Hilton MB, Wu B, Morris H, Swing DA, Zhou M, Zudaire E (2015): GPR124 functions as a WNT7-specific coactivator of canonical beta-catenin signaling. Cell Rep $\underline{10}, 123-130$

Prevo R, Banerji S, Ferguson DJ, Clasper S, Jackson DG (2001): Mouse LYVE-1 is an endocytic receptor for hyaluronan in lymphatic endothelium. J Biol Chem $\underline{276}$, 19420-19430

Rasmussen JC, Tan I, Marshall MV, Adams KE, Kwon S, Fife CE, Maus EA, Smith LA, Covington KR, Sevick-Muraca EM (2010): Human Lymphatic Architecture and Dynamic Transport Imaged Using Near-infrared Fluorescence. Transl Oncol $\underline{3}$, $362-372$

Rodriguez-Niedenführ M, Papoutsi M, Christ B, Nicolaides KH, Kaisenberg CS von, Tomarev SI, Wilting J (2001): Prox1 is a marker of ectodermal placodes, endodermal compartments, lymphatic endothelium and lymphangioblasts. Anat Embryol (Berl) 204, 399-406

Sabin FR (1902): On the origin of the lymphatic system from the veins and the development of the lymph hearts and thoracic duct in the pig. Am J Anat 1, 367-389

Saharinen P, Tammela T, Karkkainen MJ, Alitalo K (2004): Lymphatic vasculature: Development, molecular regulation and role in tumor metastasis and inflammation. Trends Immunol 25, 387-395

Schacht V, Ramirez MI, Hong Y, Hirakawa S, Feng D, Harvey N, Williams M, Dvorak AM, Dvorak HF, Oliver G (2003): T1alpha/podoplanin deficiency disrupts normal lymphatic vasculature formation and causes lymphedema. EMBO J $\underline{22}$, 3546-3556

Schneider M, Othman-Hassan K, Christ B, Wilting J (1999): Lymphangioblasts in the avian wing bud. Dev Dyn 216, 311-319

Scholzen T, Gerdes J (2000): The Ki-67 protein: from the known and the unknown. J Cell Physiol 182, 311-322

Sleeman JP, Krishnan J, Kirkin V, Baumann P (2001): Markers for the lymphatic endothelium: in search of the holy grail? Microsc Res Tech 55, 61-69

Takahashi M, Yoshimoto T, Kubo H (2004): Molecular mechanisms of lymphangiogenesis. Int J Hematol 무, 29-34 
Tammela T, Alitalo K (2010): Lymphangiogenesis: Molecular Mechanisms and Future Promise. Cell 140, 460-476

Tatin F, Taddei A, Weston A, Fuchs E, Devenport D, Tissir F, Makinen T (2013): Planar cell polarity protein Celsr1 regulates endothelial adherens junctions and directed cell rearrangements during valve morphogenesis. Dev Cell 26, 31-44

van Amerongen R, Mikels A, Nusse R (2008): Alternative Wnt Signaling Is Initiated by Distinct Receptors. Sci Signal $\underline{1}$, re9-re9

Wigle JT, Oliver G (1999): Prox1 Function Is Required for the Development of the Murine Lymphatic System. Cell $\underline{98}, 769-778$

Wilting J, Neeff H, Christ B (1999): Embryonic lymphangiogenesis. Cell Tissue Res $\underline{297}, 1-11$

Wilting J, Papoutsi M, Christ B, Nicolaides KH, Kaisenberg CS von, Borges J, Stark GB, Alitalo K, Tomarev SI, Niemeyer C (2002): The transcription factor Prox 1 is a marker for lymphatic endothelial cells in normal and diseased human tissues. FASEB J $\underline{16}, 1271-1273$

Wilting J, Hawighorst T, Hecht M, Christ B, Papoutsi M (2005): Development of lymphatic vessels: tumour lymphangiogenesis and lymphatic invasion. Curr Med Chem $\underline{12}$, 3043-3053

Witte MH, Jones K, Wilting J, Dictor M, Selg M, McHale N, Gershenwald JE, Jackson DG (2006): Structure function relationships in the lymphatic system and implications for cancer biology. Cancer Metastasis Rev 25, 159-184

Wrobel T, Dziegiel P, Mazur G, Zabel M, Kuliczkowski K, Szuba A (2005): LYVE-1 expression on high endothelial venules (HEVs) of lymph nodes. Lymphology $\underline{38}$, $107-110$

Yamaguchi TP, Bradley A, McMahon AP, Jones S (1999): A Wnt5a pathway underlies outgrowth of multiple structures in the vertebrate embryo. Development $\underline{126}, 1211-$ 1223

Yaniv K, Isogai S, Castranova D, Dye L, Hitomi J, Weinstein BM (2006): Live imaging of lymphatic development in the zebrafish. Nat Med $\underline{12}, 711-716$ 


\section{Danksagung}

Mein besonderer Dank gilt meinem Doktorvater Herrn Prof. Dr. rer. nat. Jörg Wilting für die freundliche Vergabe des Themas und die hervorragende Betreuung der Arbeit. Seine Anregungen und Kommentare waren für mich sehr hilfreich.

Bei Dr. Kerstin Buttler möchte ich mich bedanken für die Einarbeitung in die immunhistologischen Methoden und die Unterstützung in allen Bereichen. Sie hatte immer ein offenes Ohr und Lösungen für jegliche Probleme.

Bei Berti Manshausen bedanke ich mich für die freundliche Unterstützung und die gute Zusammenarbeit im Labor. 


\section{Lebenslauf}

Am 14. November 1990 wurde ich, Anna Haarmann, als erstes Kind meiner Eltern Angelika Haarmann, geb. Veddern, und Alfons Haarmann in Hamburg geboren.

Von 1997 bis 2001 besuchte ich die Grundschule Steinadlerweg und ab 2001 das Charlotte-Paulsen-Gymnasium in Hamburg, an welchem ich im Juni 2010 meine Schulausbildung mit dem Abitur beendete.

Zum Wintersemester 2010 begann ich das Studium der Zahnheilkunde an der GeorgAugust-Universität Göttingen und beendete es im November 2015 mit dem Abschluss der Zahnärztlichen Prüfung. Meine Approbation als Zahnärztin erhielt ich am 04.12.2015. Bereits während des Studiums begann ich mit den experimentellen Arbeiten $\mathrm{zu}$ meiner vorliegenden Dissertation mit dem Thema „Proliferationsuntersuchungen zur Entwicklung des Lymphgefäßsystems bei Wnt5atransgenen Mäusen “ in der Arbeitsgruppe von Herrn Prof. Dr. rer. nat. J. Wilting.

Von April 2016 bis Februar 2017 war ich als Assistenzzahnärztin in der Zahnarztpraxis Dr. Theus in Heilbad Heiligenstadt tätig. Seit März 2017 führe ich die Assistenzzeit in der Zahnarztpraxis Dr. Stock und Kollegen in Dransfeld fort. 